Universidad de Lima

Facultad de Comunicación

Carrera de Comunicación

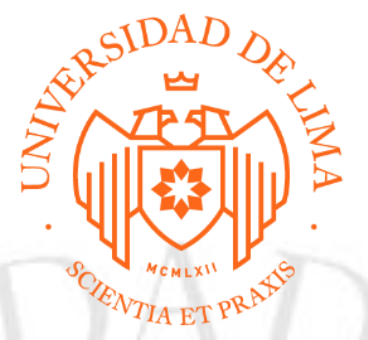

\title{
CAMPAÑA DE LANZAMIENTO DEL CONCENTRADO DE CHICHA: SEÑORA
}

\section{CHICHA}

Trabajo de Suficiencia Profesional para optar el Título Profesional de Licenciado en

Comunicación

Silvana Alexandra Castro Motta

Código 20050242

Lima - Perú

Mayo de 2019 


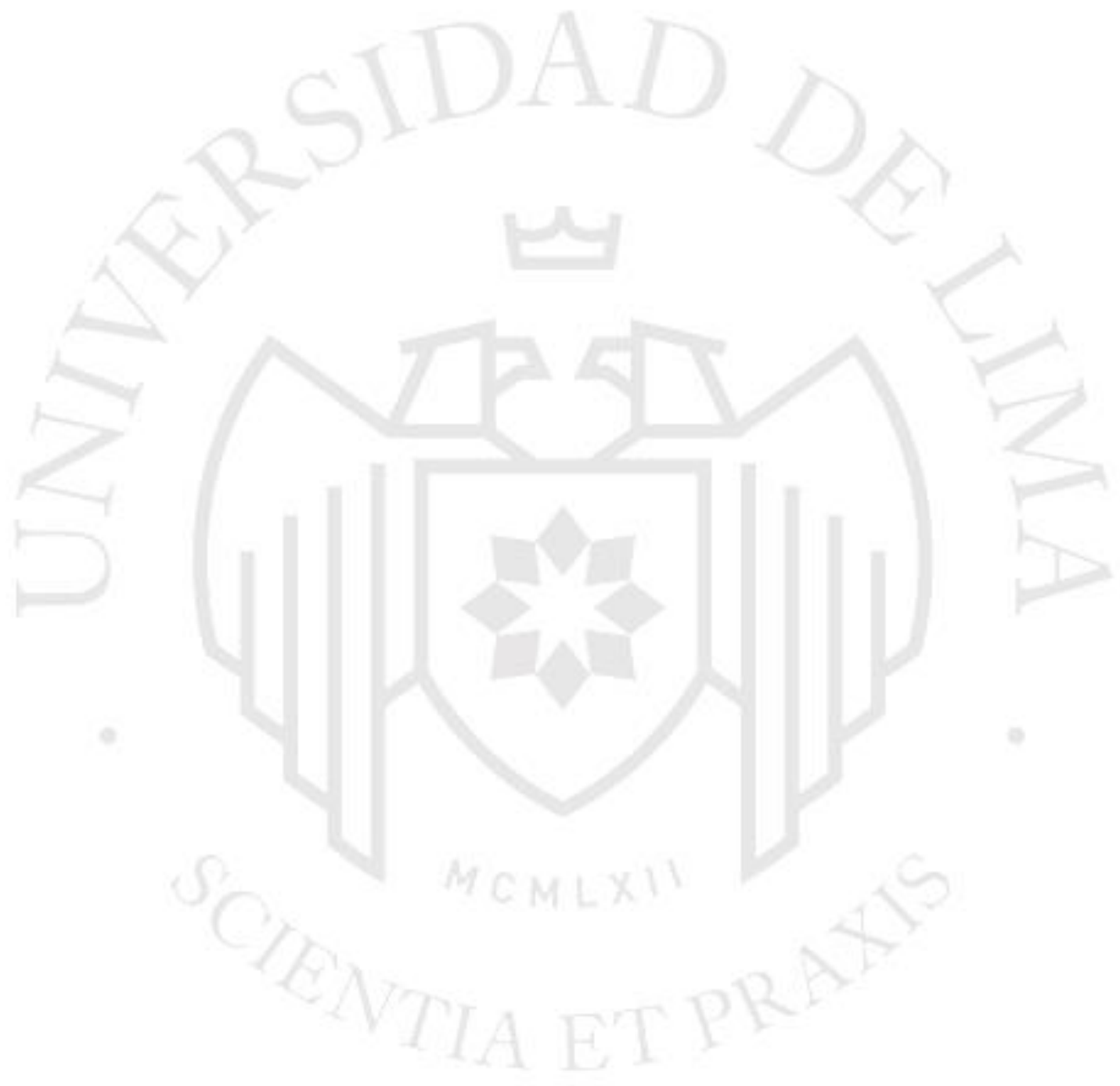




\section{CAMPAÑA DE LANZAMIENTO DEL CONCENTRADO DE CHICHA: SEÑORA CHICHA}




\section{ÍNDICE}

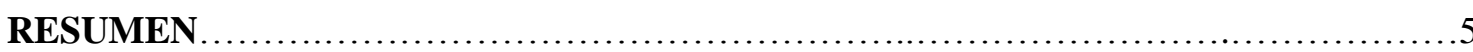

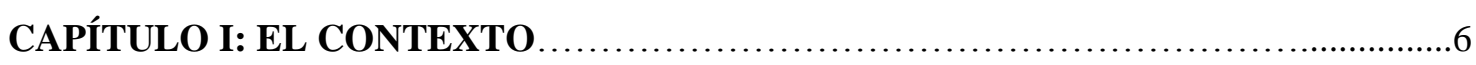

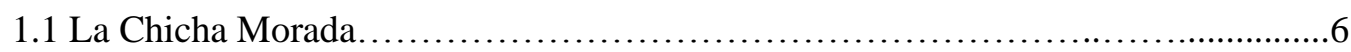

1.1.1 Sobre el maíz morado............................................

1.1.2 Receta tradicional...................................................

1.2 Análisis de la industria.................................................. 7

1.2.1 Competencia directa.............................................. 8

1.2.2 Competencia indirecta.................................................

1.3. Análisis político............................................................10

1.4 Análisis económico.........................................................11

1.5 Análisis social........................................................... 11

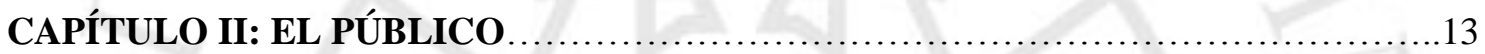

2.1 Descripción del público objetivo..........................................13

2.1.1 Percepciones del público objetivo......................................15

2.3 Buyer personas............................................................. 17

CAPÍTULO III: LA MARCA.........................................................

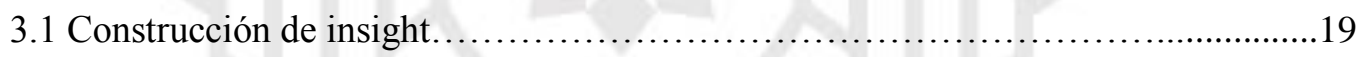

3.2 Descripción del producto...................................................19

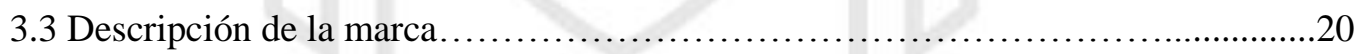

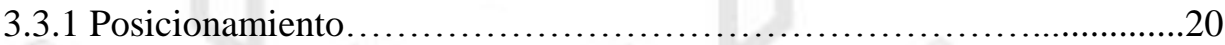

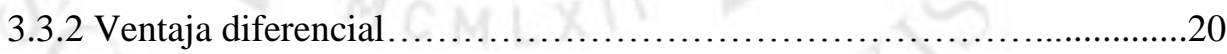

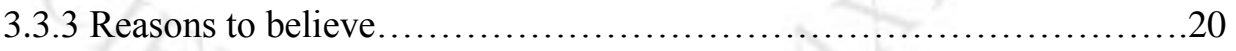

3.3.4 Personalidad de la marca..............................................20

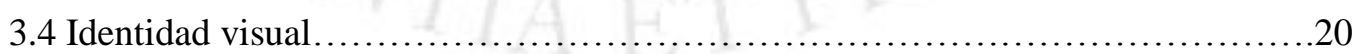

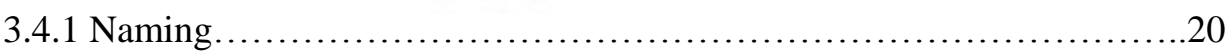

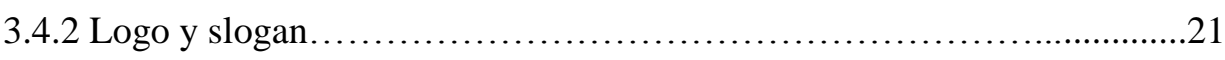

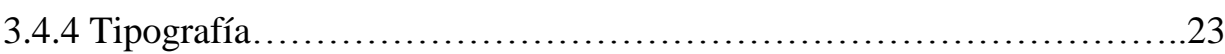

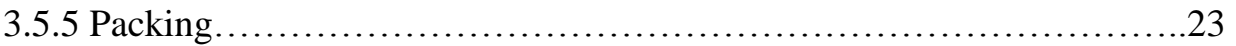




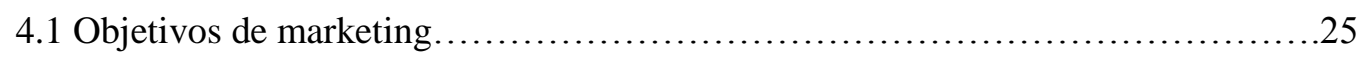

4.2 Descripción de la campaña........................................................25

\section{CAPÍTULO VI: ESTRATEGIA DE MEDIOS Y OBJETIVOS DE}

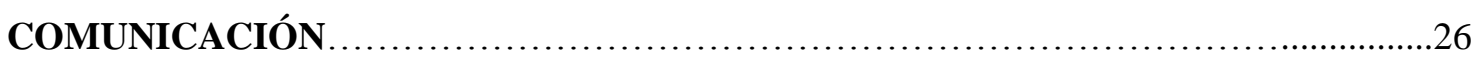

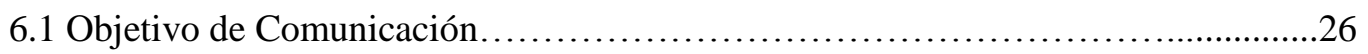

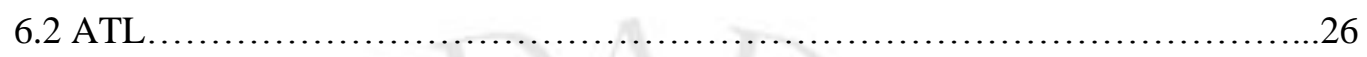

6.2.1 Televisión..........................................................26

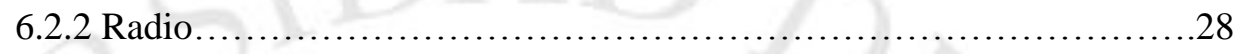

6.2 .3 Revistas.........................................................29

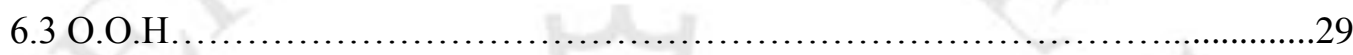

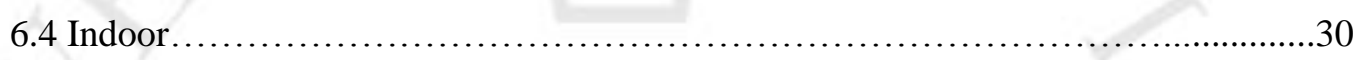

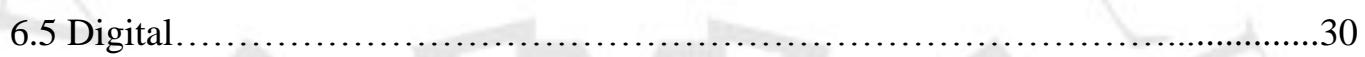

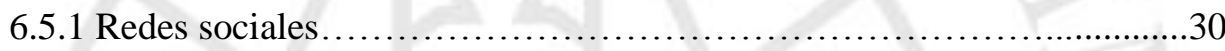

6.5.2 Google Display.....................................................

6.5.3 Landing Page.................................................... 32

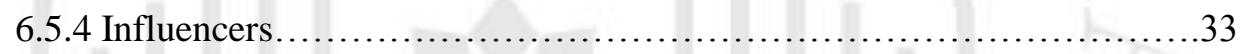

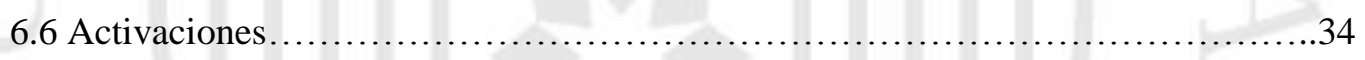

6.6.1 Mercados tradicionales.................................................34

6.6.2 Supermercados.................................................. 34

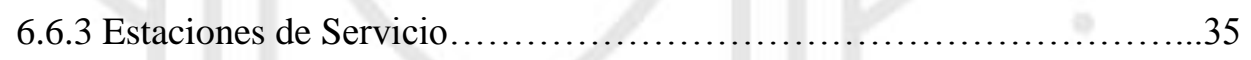

6.6.4. Casa Nestlé.................................................. 35

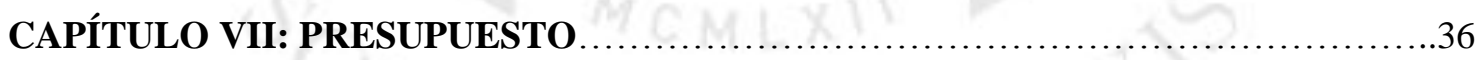

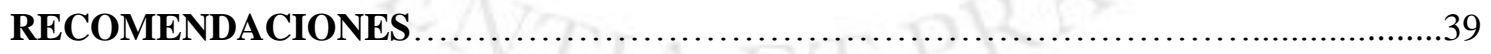

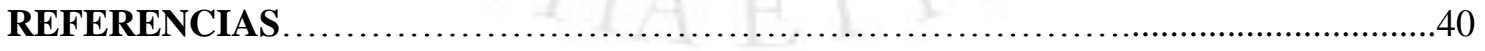

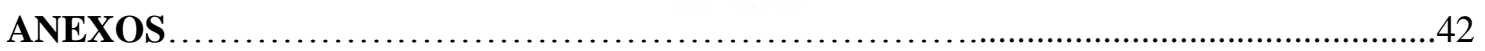




\section{RESUMEN}

El presente trabajo propone la campaña de lanzamiento de un producto único en el mercado, un concentrado de chicha natural con el verdadero sabor casero, además en el contexto actual, el atributo de “cero azúcar añadido” resulta atractivo. En el desarrollo de las acciones comunicativas se busca destacar el máximo valor de la nueva ama de casa y la mujer detrás de ella. A continuación conocerán a una marca que realmente entiende a su público objetivo. 


\section{CAPÍTULO I \\ EL CONTEXTO}

\subsection{La Chicha Morada}

La chicha morada es una bebida tradicional de la cultura peruana, forma parte importante de la amplia despensa natural de nuestro país y es reconocida como la bebida bandera. A lo largo de la historia se le ha dado un lugar protagónico como acompañante ideal de nuestra comida típica. Sin embargo, no está presente en la mesa de los hogares peruanos desde tiempos recientes, sino que trae consigo una rica historia que inicia en los andes peruanos, donde crece el insumo principal: el maíz morado.

\subsubsection{Sobre el maíz morado}

Este rico cereal se siembra principalmente en Huánuco, y 7 departamentos más: Lima, Ica, Arequipa, Ancash, La Libertad, Cajamarca y Ayacucho, en los meses de agosto a octubre en la sierra y en los meses de abril a septiembre en la costa. Desde el año 2009, año desde donde se tiene data de producción, la cosecha ha ido en aumento. Nuestro maíz morado también es altamente valorado en el exterior, siendo Estados Unidos, Ecuador y España los principales países destino de las exportaciones del cereal.

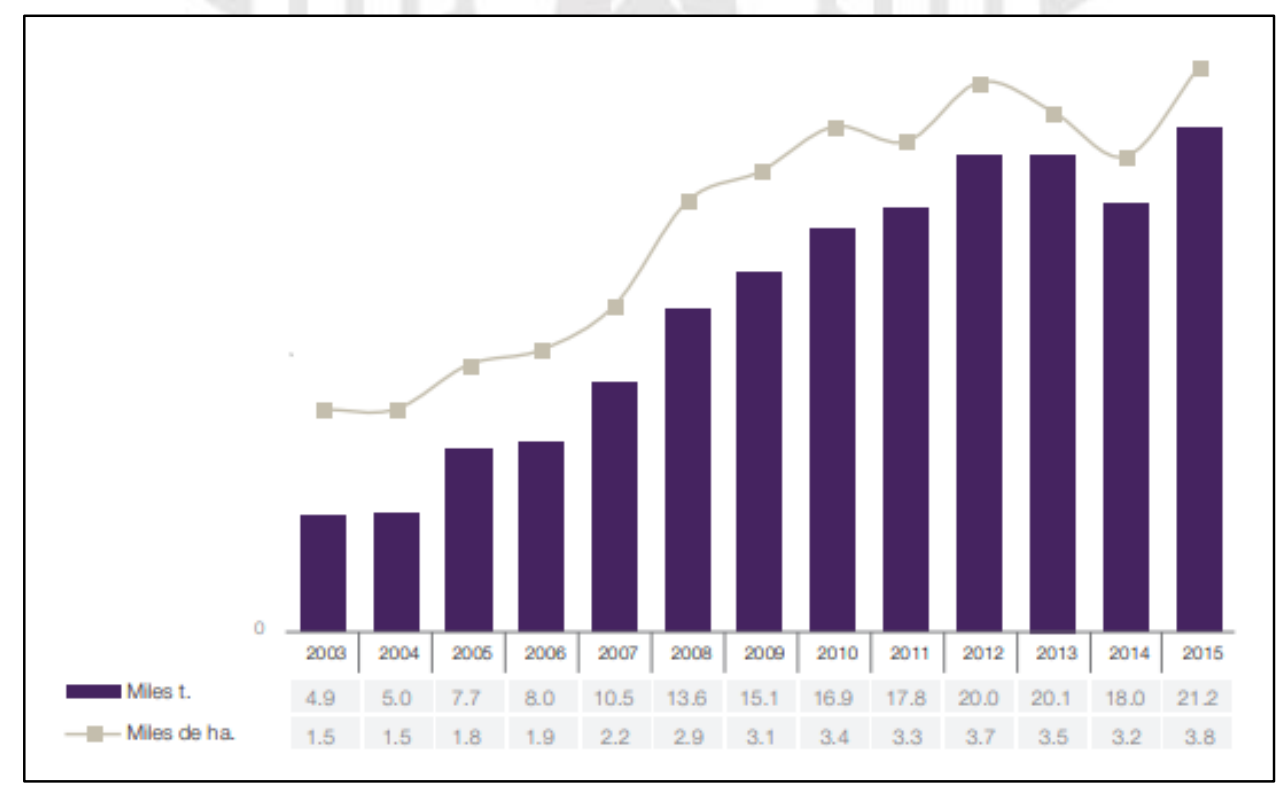

Figura 1: Evolución de la producción y de la superficie cosecha nacional.. Fuente: Ministerio de Agricultura.

Muy poco se han difundido las infinitas propiedades de este potente cereal, el cual tiene un alto valor nutricional que va desde su contribución para la formación de colágeno hasta su efecto 
preventivo frente al cáncer. El Zea Mays, por su nombre en quechua, también reduce el colesterol y aporta beneficios ante las enfermedades cardiovasculares. M.Granados, nutricionista particular, destaca la acción antioxidante de la chicha y lo considera una excelente alternativa como colorante natural (comunicación personal, 01 de mayo de 2019).

\subsubsection{Receta tradicional}

Las familias tradicionales de nuestro país la han aprendido a preparar en casa, convirtiéndose en una receta que conserva los secretos de antaño que le da ese toque diferente a la tan valorada bebida.

Los ingredientes que se requieren para su elaboración son:

- $1 \mathrm{Kg}$. de maíz morado

$\mathrm{S} / 6$

$-1 / 2$ piña (cascara)

$\mathrm{S} / 5.50$

- 1 membrillo

$\mathrm{S} / 1$

- 3 manzanas de agua

$\mathrm{S} / 1$

- 1 rama de canela entera

$\mathrm{S} / 0.80$

- 3 limones

$\mathrm{S} / 1$

Estas cantidades rinden aproximadamente para 2 litros de Chicha Morada, la preparación podría sonar simple, pero el tiempo de espera es lo que la torna un tanto tediosa. La receta indica que deben hervirse todos los ingredientes juntos durante 45 minutos, (maíz morado, cascara de piña, manzanas, membrillo y canela) pero si se desea un resultado con mayor concentración, se recomienda hervir 1 de las mazorca sin granos. En promedio el costo de prepararla de manera casera es de $\mathrm{S} / 15.30$.

\subsection{Análisis de la industria}

El sector de consumo masivo en el Perú es uno de los que experimenta una mayor y más agresiva competencia, en el mercado de bebidas encontramos categorías como gaseosas, agua embotellada, infusiones, jugos listos, néctares, rehidratantes, instantáneos, concentrados, entre otros. Sin embargo hay que tener presente que "existe una tendencia hacia el consumo de lo natural" (Arellano, 2019), es por ello que muchas de las marcas han apostado por desarrollar las variables "light", "cero azúcar" o "endulzadas naturalmente" para sus productos. 
PROYECCIÓN DE VENTA EN CANAL OFF-TRADE POR CATEGORÍA

\begin{tabular}{lcccccc} 
Millones de soles & $\mathbf{2 0 1 5}$ & $\mathbf{2 0 1 6}$ & $\mathbf{2 0 1 7}$ & $\mathbf{2 0 1 8}$ & $\mathbf{2 0 1 9}$ & $\mathbf{2 0 2 0}$ \\
\hline Botella de agua & $1,139.8$ & $1,252.0$ & $1,362.4$ & $1,476.6$ & $1,595.8$ & $1,721.3$ \\
\hline Carbonatada & $3,352.1$ & $3,399.8$ & $3,417.6$ & $3,455.3$ & $3,508.8$ & $3,576.0$ \\
\hline Concentrados & 80.5 & 80.7 & 80.6 & 80.7 & 81.2 & 81.9 \\
\hline Jugos & 903.5 & 930.9 & 948.8 & 969.8 & 994.0 & $1,021.4$ \\
\hline Café envasado & 0.4 & 0.4 & 0.4 & 0.4 & 0.4 & 0.5 \\
\hline Té envasado & 366.8 & 425.9 & 489.7 & 555.3 & 622.5 & 691.3 \\
\hline Bebidas energéticas & 878.0 & 960.7 & $1,043.9$ & $1,128.7$ & $1,513.8$ & $1,598.9$ \\
\hline Bebidas especiales de Asia & - & - & - & - & - & - \\
\hline Total & $\mathbf{6 , 7 2 1 . 1}$ & $\mathbf{7 , 0 5 0 . 3}$ & $\mathbf{7 , 3 4 3 . 4}$ & $\mathbf{7 , 6 6 6 . 8}$ & $\mathbf{8 , 3 1 6 . 6}$ & $\mathbf{8 , 6 9 1 . 2}$ \\
\hline
\end{tabular}

Figura 2: Proyección de venta en canal off-trade por categoría. Fuente: Perú - Retail.

Se afirma en un estudio presentado por la Consultora Nielsen que el $90 \%$ de consumidores peruanos están dispuestos a pagar más por productos que aportan beneficios para su salud. (Diario Gestión 2017).

\subsubsection{Competencia directa}

El principal mercado que debemos explorar para el lanzamiento del producto es el de los Concentrados de chicha. Hay que tener en cuenta que existen muchas empresas que lo producen pero enfocado a ventas $\mathrm{B} 2 \mathrm{~B}$, que para efectos de esta investigación no se han considerado. En ese sentido, se describen a continuación las marcas identificadas:

- Sayani: ofrece concentrados de chicha natural en presentaciones desde $200 \mathrm{ml}$, hasta 5 ltrs. En su comunicación la empresa apela al origen quechua de su nombre que significa "el que se mantiene de pie", también resalta su preocupación por brindarle a su público productos de alto valor nutricional.

- Valle Fértil: se posiciona como la mejor seleccionadora de frutas de calidad, tiene un portafolio que va más allá de los concentrados y destaca su preocupación por el medio ambiente en sus envases de vidrio. La chicha morada que ofrecen la venden en presentación de 1 lt. Cabe destacar que esta marca distribuye sus productos en supermercados o tiendas especializadas en cuidado la salud. 
- Naturale: son los líderes en la categoría de concentrados, están presente en el mercado peruano desde hace más de 15 años, participan en la venta B2C y B2B. Cuentan con bebidas RTD (Ready To Drink) en diferentes sabores como piña, maracuyá, manzana y emoliente posicionándose así como los de "sabor natural". El concentrado de chicha morada lo venden en presentación de botella de 1lt. y bolsa de 2 ltrs. y están distribuidos en supermercados Wong, Metro y Plaza Vea. En su comunicación priorizan el bajo porcentaje de calorías y su atributo principal es el " $0 \%$ de azúcar añadida".

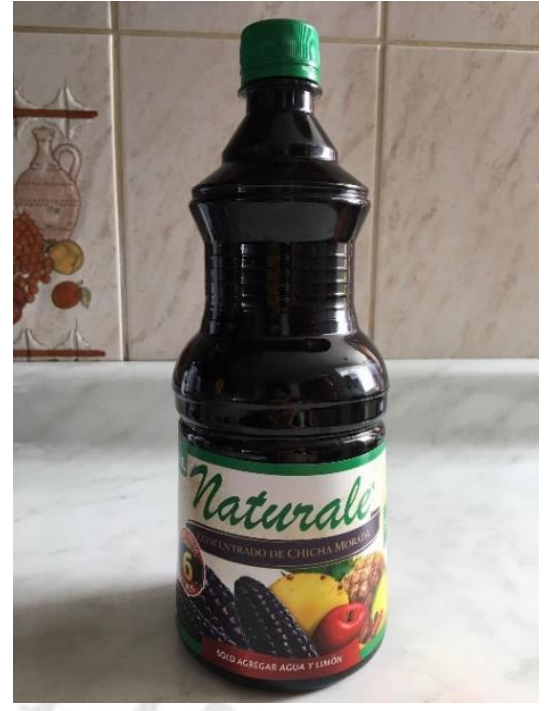

Foto propia. Botella de 1lt.

Cabe mencionar que como producto de esta etapa de investigación, se identificó la venta de concentrado de chicha morada en bolsa en los principales mercados de los distritos de las Zonas 4 y 10 según clasificación de APEIM (2018), donde se albergan el mayor porcentaje de hogares de NSE C.

\subsubsection{Competencia indirecta}

A pesar que el producto propuesto en este proyecto es un concentrado de chicha morada, es necesario tener mapeado a los productos RTD ya que muchos de estos cumplen las exigencias del público objetivo al destacar sus propiedades naturales y además son más fáciles de encontrar.

\begin{tabular}{|c|c|c|c|c|}
\hline MARCA & KERO & FRUMÁS & GLORIA & NATURALE \\
\hline \multicolumn{5}{|l|}{ FOTO } \\
\hline OBSERVACIÓN & $\begin{array}{l}\text { En su etiqueta destaca que es } \\
\text { un producto endulzado con } \\
\text { stevia y no contiene } \\
\text { saborizantes ni colorantes. } \\
\text { Desde su nombre apela a lo } \\
\text { peruano. }\end{array}$ & $\begin{array}{l}\text { En su etiqueta resalta que es } \\
\text { "100\% maiz morado", el nombre } \\
\text { de la marca remite a lo natural } \\
\text { y tiene una gráfica bastante } \\
\text { fresca. }\end{array}$ & $\begin{array}{l}\text { La marca tiene respaldo y es } \\
\text { identificada como una marca } \\
\text { peruana representativa. En su } \\
\text { línea de refrescos caseros } \\
\text { presentan su chicha como } \\
\text { "concentrado de maiz morado y } \\
\text { frutas". }\end{array}$ & $\begin{array}{l}\text { Tal como se mencionó en el } \\
\text { punto anterior, las bebidas RTD } \\
\text { de Naturale tienen un espacio } \\
\text { ganado en la mente del } \\
\text { consumidor como lo más natural. } \\
\text { El diseño de su etiqueta hace } \\
\text { sentir lo artesanal del producto } \\
\text { haciendo más creíble el mensaje } \\
\text { que la acompaña "sin } \\
\text { saborizantes". El diseño de su } \\
\text { envase te remite a la mazorca del } \\
\text { maiz morado. }\end{array}$ \\
\hline
\end{tabular}

Figura 3: Descripción de las principales bebidas RTD. Elaboración propia. 
Para cerrar el análisis general del entorno en el que se lanzará el nuevo producto de concentrado de chicha se ha realizado un análisis a nivel político, económico y social:

\subsection{Análisis político}

- $\quad$ Ley de Promoción de Alimentación Saludable. Ley N 30021

"Tiene como objeto la promoción y protección efectiva del derecho a la salud pública al crecimiento y desarrollo adecuado de las personas, a través de las acciones de educación, el fortalecimiento y fomento de la actividad física, la implementación de kioscos y comedores saludables, en las instituciones de educación básica regular y la supervisión de la publicidad y otras prácticas relacionadas con los alimentos, bebidas no alcohólicas dirigidas a niños, niñas y adolescentes para reducir y eliminar las enfermedades vinculadas con el sobrepeso, la obesidad y las enfermedades crónicas conocidas como no transmisibles". (Decreto Supremo que aprueba el Reglamento de la Ley Nº 30021)

\section{- Manual de Advertencias Publicitarias}

El Reglamento de la Ley No 30021, Ley de Promoción de la Alimentación Saludable para Niños, Niñas y Adolescentes aprobado con Decreto Supremo No 017- 2017-SA establece que los alimentos procesados llevarán advertencias publicitarias. El artículo 15 del precitado Reglamento precisa que las advertencias publicitarias serán aplicables a aquellos alimentos procesados cuyo contenido de sodio, azúcar, grasas saturadas y grasas trans excedan los parámetros técnicos establecidos. (Decreto Supremo que aprueba Manual de Advertencias Publicitarias)

- Formato de las advertencias

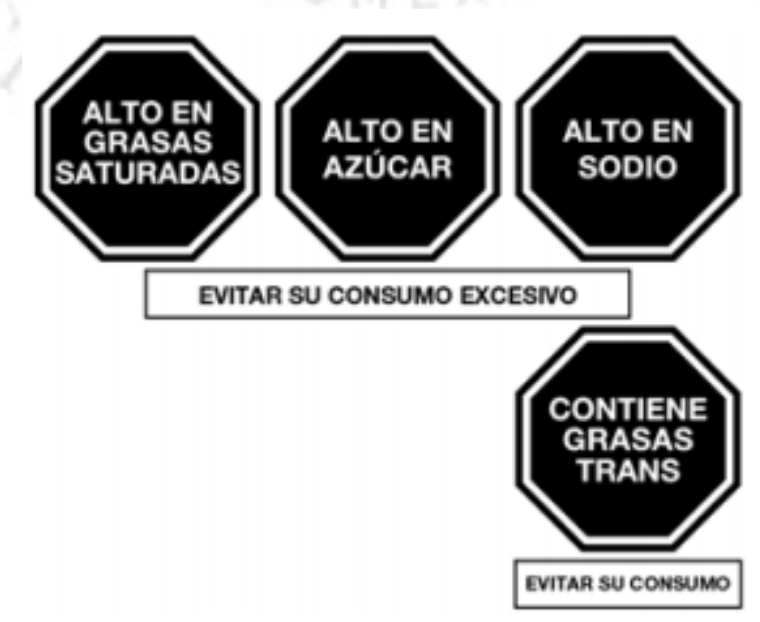

Figura 4: Formato de las advertencias publicitarias en los alimentos procesados. Fuente: Diario El Peruano. 
- Regularización a los influencers

Recientemente el Instituto Nacional de Defensa de la Competencia y de la Protección de la Propiedad Privada ha anunciado que este año iniciará la supervisión de publicidad y recomendaciones de marcas que promocionan los influencers en sus cuentas.

\subsection{Análisis económico}

- La canasta básica está conformada por alimentos de primera necesidad como: lácteos, carnes, huevos, cereales, azúcar, verduras y frutas.

- En la actualidad se ha puesto sobre la mesa el debate de la actualización de la canasta básica familiar en nuestro país. INEI iniciará un proceso de encuestas para establecer un nuevo patrón de consumo de los hogares peruanos.

- Diferentes informes revelan que la canasta básica en el Perú se encuentra en el ranking de las más costosas en Latinoamérica (Diario La República 2019).

- “En una comparación entre salario mínimo y canasta básica en Latinoamérica que realizó la OIT, el Perú no está entre los mejores países" (Cámara de Comercio de Lima, 2019).

- Los niveles socioeconómicos establecidos en el informe de APEIM (2018) estable que los distritos de Surco, Miraflores, San Borja, San Isidro y La Molina albergan al 51\% de la población de NSE A y Villa El Salvador, Lurín, Pachacamac el 52.2\% de peruanos en NSE C.

\subsection{Análisis social}

- Un primer punto muy importante para el análisis social es considerar que el concepto de ama de casa ha cambiado. El ama de casa moderna no es la que se dedica únicamente al hogar ni la que necesariamente tiene hijos.

- En el Perú se habla con más fuerza del "feminismo" y "empoderamiento femenino" pues hoy en día la mujer es multidisciplinaria, busca destacar en cada aspecto de su vida sin restringirse a un único rol en la sociedad. respecto R. Sorogastúa, comunicadora y coach certificada, define el feminismo como la vertiente radical en la que no se considera 
necesaria la energía del hombre y al empoderamiento lo vincula con lo referido a la igualdad de oportunidades (comunicación personal, 03 de mayo de 2019).

- Kantar Worldpanel realizó un estudio sobre el estilo de vida de las peruanas, en el que precisa que el $46 \%$ de mujeres son amas de casa y también salen a trabajar, además detalla que 3 de cada 4 son mamás y que trabajan por necesidad, sin embargo disfrutan su trabajo e independencia económica que ello les brinda. (Kantar Worldpanel, 2017) 


\section{CAPÍTULO II EL PÚBLICO}

\subsection{Descripción del público objetivo}

De acuerdo al brief recibido, el producto que se desea introducir en el mercado está dirigido a amas de casa de NSE A, B y C modernas y prácticas. Sin embargo para este proyecto se ha visto conveniente delimitar el público objetivo a amas de casa entre 30 y 40 años con 1 u 2 hijos, que viven en Lima Metropolitana y que además de encargarse de las tareas del hogar, se desarrollan en otros ámbitos, como por ejemplo, el profesional, el de mamá, esposa, e hija, buscando destacar en cada uno.

Es una mujer actual que rompe los estereotipos convencionales y se reinventa cada día, conoce bien sus fortalezas y falencias. Tal como lo menciona Cristina Quiñones (2019) en su reciente libro: "cada vez vemos más mujeres que se identifican menos con mujeres maravilla (perfectas) y se sienten mejor viéndose representadas con mujeres reales" (p. 193)

Según la clasificación de los estilos de vida de Arellano, el público objetivo está perfectamente descrito bajo el estilo de "Las Modernas":

Mujeres que trabajan o estudian y que buscan su realización personal también como madres. Se maquillan, se arreglan y buscan el reconocimiento de la sociedad. Son modernas, reniegan del machismo y les encanta salir de compras, donde gustan de comprar productos de marca y, en general, de aquellos que les faciliten las tareas del hogar. (Arellano, 2018)

\section{La tecnológica}

En cuanto al acceso a la tecnología, Kantar IBOPE medía indica que se trata de mujeres multipantalla que pasan entre 2 y 3 horas al día en redes sociales. Cuentan con un smartphone con el que realizan múltiples actividades, además de comunicarse, lo usan para mantenerse informadas y hasta realizan compras online lo cual es una tendencia que va en aumento. (Gestión, 2017) Además, 45\% pertenecen a una red social, están más conectadas y familiarizadas con Facebook, Instagram y Youtube, consideran que la tecnología aporta en el quehacer diario y se apoyan en ella para resolver su día a día. 


\section{La mamá}

Hay que tener en cuenta que si bien estamos describiendo a amas de casa (mujeres con más responsabilidades) se trata también de madres. Como se mencionó previamente, el público objetivo está delimitado en el rango de edad de 30 a 40 años, por lo cual estamos hablando de mujeres millennials que tienen una forma particular de concebir la maternidad, a diferencia de generaciones anteriores. Este grupo generacional comparte las funciones que trae consigo la paternidad y no la considera responsabilidad exclusiva de las madres, "no se trata de un cambio de funciones, sino algo más profundo: un cambio de mentalidad" (Cristina Quiñones, 2019, p. 216).

También utilizan las redes sociales para absolver dudas y compartir inquietudes sobre sus hijos, sobretodo las mamás primerizas. Otra característica importante es que son más prácticas en cuanto a la crianza y suelen inscribirlos en múltiples actividades extracurriculares. Se preocupan por formar niños más independientes y emocionalmente estables, acuden a estimulaciones tempranas. Estas nuevas mamás no olvidan su vida personal por el hecho de convertirse en madres, sino que se convierte en un reto más para ellas.

\section{La profesional}

El deseo de continuar o culminar sus estudios es peregne, la mayoría tiene la mirada puesta en lograr superarse en lo profesional y obtener mejores oportunidades laborales. Incluso se sabe que las mamás que se desenvuelven en un entorno laboral son más activas en redes sociales y plataformas como LinkedIn entran en el panorama. Acceden a internet ya no sólo a través de su Smartphone sino también por medio de computadoras o laptops. (Merca 2.0, 2017)

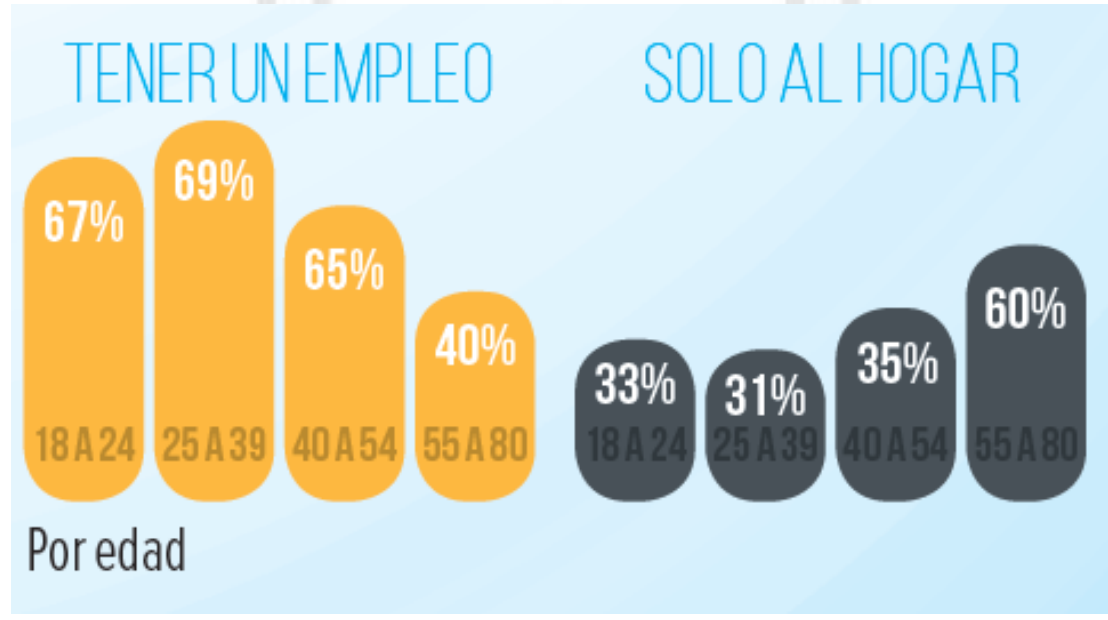

Figura 6: Amas de casa desean dejar el nido y vuelan muy alto. Fuente: Ipsos 2018. 


\section{La wellness}

Desde antes que se promulgara la Ley de Promoción de Alimentación Saludable, en los hogares limeños ya existía la preocupación por la nutrición. De acuerdo a una investigación realizada por Kantar Worldpanel, "el $87 \%$ de hogares peruanos piden a los fabricantes que desarrollen productos más nutritivos; frente al 53\% que requiere productos más económicos; el 21\% que pide productos más prácticos” (Mercado Negro, 2018)

El hábito de leer la información nutricional de cada producto se encuentra muy frecuentemente en el público objetivo, ellas se orientan más por los productos con una promesa nutritiva. Esta premisa se respalda en el reporte realizado por Kantar, el cual revela que el 60\% de amas de casa prefiere darles a sus hijos alimentos naturales. (Kantar, 2019)

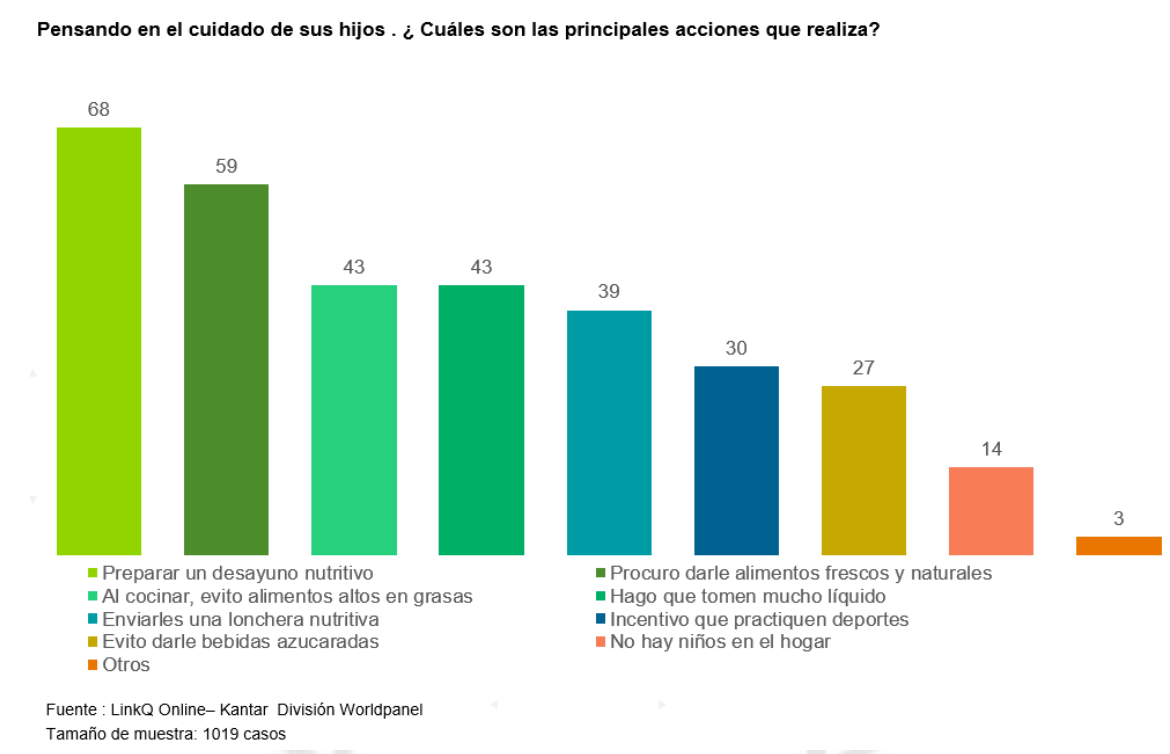

Figura 7: ¿Cómo cuidan las peruanas a sus hijos?. Fuente: Kantar 2019.

\subsubsection{Percepciones del público objetivo}

Se aplicaron 34 encuestas al público objetivo y de éstas se sacaron algunas importantes conclusiones que se detallan a continuación:

- Sólo 1 de las encuestadas se reconoció como "ama de casa", lo cual confirma que el público objetivo no se ve reflejada en este rol.

- Todas tienen una actividad favorita que realizan en sus tiempos libres, las que más se repitieron son: hacer deporte, ver televisión y pasar tiempo en familia. 
- En cuanto a sus preferencias para hacer las compras del hogar, $88.2 \%$ las prefiere hacer en supermercados mientras que el $35.3 \%$ opta por ir a los mercados tradicionales. $20.6 \%$ menciono que los mercados orgánicos y eco ferias también se han vuelto una opción para sus compras.

- El valor nutricional, la calidad y las bajas calorías son la principal preocupación de las encuestadas al momento de elegir un producto para el consumo de sus hijos.

- Muchas de ellas hicieron hincapié en que descartan los productos con saborizantes artificiales y en caso se vieran en la necesidad de adquirir alguno, preferirían los que indican ser endulzados naturalmente o de manera "light".

- Entre las características de Precio, Ingredientes, Sabor y Marca de una bebida, el 76.5\% toma como prioritario los ingredientes como lo más relevante.

- Es interesante conocer que el $44.1 \%$ si ha preparado la chicha de manera tradicional alguna vez, pero sin embargo lo considera un procedimiento trabajoso. El 17.6\% desearía aprender a hacerla y el $11.8 \%$ elige comprarla lista.

- En cuanto a la estación ideal para su consumo, les es indiferente, pero si tuvieran que elegir una sería el verano.

- Los beneficios de la chicha morada para la salud son conocidas por el $55.9 \%$ de amas de casa encuestadas.

- Se les consulto también por el beneficio que más destacan de la chicha morada, entre las opciones tuvieron: anti-envejecimiento, antioxidante, mitiga problemas musculares, reduce los niveles de colesterol malo, estimula la acción diurética, previene el cáncer. Siendo su función antioxidante la que más apreciaron un 37.5\%. 


\subsection{Buyer personas}

Luego de conocer de manera más profunda al público objetivo, se han desarrollado 2 buyer persona:

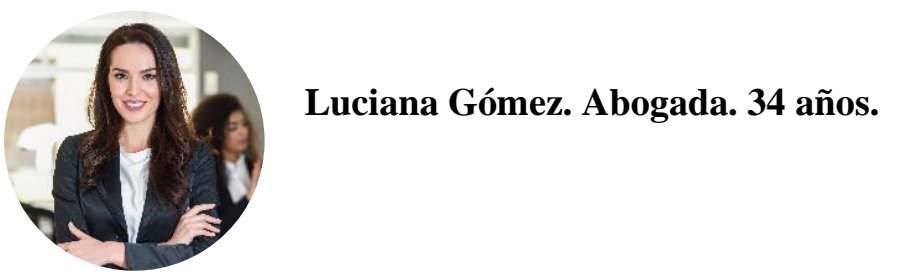

Está casada hace 5 años, tiene un hijo de 4 años y planea tener otro en el corto plazo. Su esposo también es abogado, ambos son trabajadores dependientes.

Ella es súper activa, por ello como parte de su rutina diaria, incluye el deporte. Todos los días se levanta muy temprano para ir al gimnasio donde gusta de practicar Tae bo, spinning y yoga.

Luciana se moviliza en auto propio, cada mañana deja a su hijo en el nido y su mamá la apoya recogiéndolo y cuidándolo hasta que ella o su esposo lleguen de regreso del trabajo. No tiene un horario fijo de salida, pero cuando encuentra tráfico escucha la radio para aliviar el trayecto.

El trabajo de Luciana implica muchos viajes al interior del país, por lo que organizar las compras de su casa y sus propias necesidades resultan vital. Los días domingo son los elegidos por ella para hacer compras semanales.

Usa redes sociales, tiene perfiles en Facebook, Instagram y LinkedIn. Generalmente comparte fotos de momentos familiares, selfies y frases de empoderamiento. Lee portales web de los principales diarios y sigue algunos vloggers de salud, estilo, y mamás principalmente en Instagram.

En cuanto a la alimentación de su pequeño hijo, hasta el momento ha evitado los dulces y golosinas en su alimentación, para compensar el dulce, ella le da frutas.

Para ella su hijo es su prioridad pero eso no la detiene en la búsqueda de sus sueños, por ello ha desarrollado un proyecto propio junto con una gran amiga, se trata de una marca de accesorios para mujer. Este proyecto combina perfecto con su gusto por la moda.

En sus tiempos libres le gusta leer, avanza trabajo de la oficina, le gusta la fotografía y llevar a pasear a su hijo a lugares de arte para niños como micro teatros infantiles y otros parecidos. 


\section{Mirella Neyra. Secretaria. 40 años.}

Mirella es mamá de 2 niñas, una de 12 años y otra más pequeña de 7 . Hace 4 años se divorció y desde entonces decidió llevar a su mamá a vivir con ella (su papá falleció hace varios años).

Vive en Chorrillos, trabaja en una consultora en San Isidro, su rutina durante los días de semana empieza con la preparación de las loncheras, le gusta asegurarse que sus hijas estén correctamente alimentadas porque además las ha inscrito en natación y gastan mayor energía.

Una compañera de trabajo vive cerca a su casa y la jala todos los días, en el camino escuchan noticieros y al regreso procuran almenos dos veces por semana salir al correr por el malecón del distrito. Desde que se divorció despertó en ella una mayor preocupación por sí misma a nivel personal y profesional, por ello busca constantemente en internet cursos cortos para estudiar.

En cuanto a su vida social, se suele reunir por lo menos 1 vez al mes con sus amigas y mantiene constante comunicación con las demás mamás del colegio de sus hijas, de esta forma se mantiene al tanto de las actividades y resulta para ella un gran canal para estar informada ya que debe cumplir un horario de oficina que no es muy flexible.

Usa redes sociales, tiene perfiles en Facebook, e Instagram. Comparte muy poco contenido pero si está pendiente de las amigas e influencers que sigue, entre sus favoritos están las de estilo y moda, las mamás blogueras y artistas de televisión.

Las compras del hogar las realiza fines de semana, ciertos productos los compra en el supermercado y otros en el mercado tradicional de su distrito.

$\mathrm{Su}$ familia es grande y unida, por lo general suelen almorzar los domingos todos juntos en casa de su hermana o de su tía. Otra actividad que disfruta en sus tiempos libres es ver películas y series con sus hijas.

Además de trabajar de manera dependiente, Mirella es representante de ventas de Natura (venta por catálogo), esto representa un ingreso extra para ella. 


\section{CAPÍTULO III \\ LA MARCA}

\subsection{Construcción de insight}

A partir del conocimiento del público objetivo antes detallado, se presenta un esquema de construcción del concepto de la marca partiendo de los principales insights encontrados:

\section{Insights del ama de casa moderna}

- La alimentación saludable es un punto importante para sí mismas y para sus hijos.

- Piensan en alimentos que sean una real fuente de nutrición.

- Quieren darles tiempo de calidad a su familia.

- Valoran las actividades que pueden generar ahorro de tiempo.

- Se sienten en la capacidad de tener todo bajo control.

- La planificación del día a día es clave para llevar a cabo todo lo que se proponen.

- Les gusta ser reconocidas y valoradas.

\section{Verdad oculta}

"Tengo tantas actividades por cumplir en el día que temo descuidarme de darle a mi familia productos realmente saludables"

\section{Idea general}

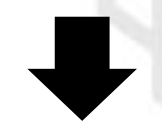

Presentarle al ama de casa moderna un producto que la entienda y hable su mismo lenguaje, una experta en nutrición que se vuelva su aliada en el día a día.

\section{Concepto}

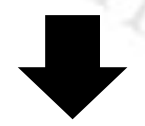

Te comprendo, soy experta como tú.

\subsection{Descripción del producto}

Señora Chicha es un concentrado de chicha verdaderamente natural, es un nuevo producto de Nestlé Perú, la empresa líder en nutrición, salud y bienestar. Bajo su estrategia de sumar productos que se identifiquen con la región de operación, nació la idea de introducir al mercado la bebida tradicionalmente peruana en una versión de "concentrado" lista para servir y compartir 
en familia, sin azúcar añadida y revalorizando el poder nutritivo de la chicha. Una de las características principales del producto es que está elaborada con los granos de maíz morado, membrillo, manzana y canela y está perfectamente alineada al mensaje de bienestar de la empresa.

\subsection{Descripción de la marca}

La marca Señora Chicha busca proyectar confianza y tranquilidad a las amas de casa que gustan de consumir productos saludables, personifica a una experta en nutrición que te da una "mano" con ese aspecto para que continúes ocupándote en tu crecimiento personal y profesional sin preocupaciones extra.

\subsubsection{Posicionamiento}

Para las amas de casa modernas y activas, Señora Chicha es la chicha tradicional de antaño lista para servir. Les da la seguridad de estar brindándole a su familia lo verdaderamente sano y natural.

\subsubsection{Ventaja diferencial}

Señora Chicha es un concentrado de chicha morada hecho de manera natural sin azúcar añadida.

\subsubsection{Reasons to believe}

- El concentrado de chicha tiene no contiene azúcar añadida.

- Está elaborada con ingredientes naturales, sin preservantes.

- La empresa Nestlé cuenta con una reputación ganada y es dueña del concepto "nutrición y bienestar".

\subsubsection{Personalidad de la marca}

Es moderna, fresca, ágil, y directa en su comunicación, es una mujer experta en nutrición por eso siempre tendrá el tip perfecto. Es cercana y confiable.

\subsection{Identidad visual}

Para desarrollar la identidad visual de la marca se tomó en cuenta la imagen de las principales marcas competidoras, la gran mayoría comparten la idea en común de tener presente al insumo principal en su presentación y utilizan recursos gráficos que apelan a lo natural.

\subsubsection{Naming}

El nombre elegido para este concentrado de chicha fue "Señora Chicha". Antes de llegar a esta elección se evaluaron nombres quechuas buscando destacar peruanidad, que muchas veces es 
asociado con alimentos A1 por lo popular de nuestra gastronomía, pero la terminología no destaca en la categoría de bebibles (ya existe Kero) ni resultaba cercano para el perfil al que nos dirigimos. Por su parte, Señora Chicha, cumplía con la idea de rendidora si pensamos en el producto como una persona "LA señora chicha". Por si misma, la palabra "señora" trae consigo una connotación de experiencia, sabiduría y confiabilidad que va más alineado con nuestro posicionamiento y concepto.

\subsubsection{Logo y slogan}

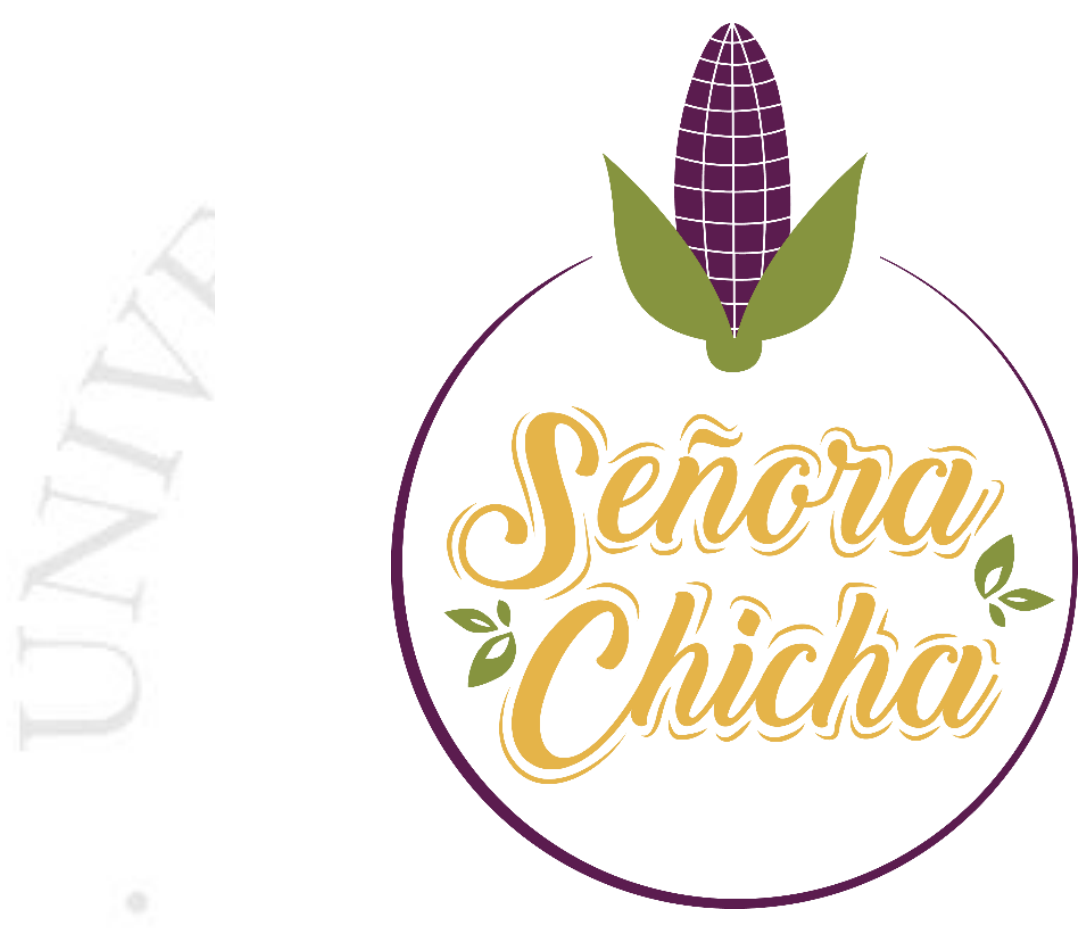

Se trata de un logo del tipo descriptivo y tipográfico. Tiene como isotipo al maíz morado que en una siguiente etapa se buscará posicionarlo para un fácil reconocimiento de la marca, algo que la competencia no maneja (logos tipográficos). Otro elemento importante es el círculo que engloba al nombre, este recurso tiene la función de recordarnos que es un concentrado que inicia y termina con el maíz.

La paleta de colores utiliza la combinación de colores cálidos y fríos para un armónico balance visual:

- Morado: está presente para recordarnos el origen de la chicha: el maíz morado. Además, según la psicología del color, transmite sabiduría.

- Amarillo: transmite energía, la misma que tiene en su día a día nuestro público objetivo, tal y como lo menciona Villfaña (2007): "el amarillo representa la luz y la energía” (p. 42). 
- Verde: en el logo propuesto, tiene la misión visual de bajar la intensidad del amarillo y acompañar al soporte gráfico que acompaña la tipografía. Naturalmente es un color que simboliza la naturaleza y salud,

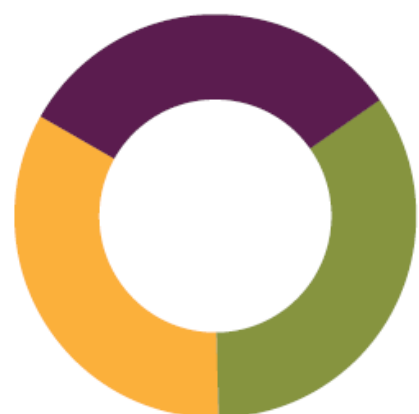

$\begin{array}{llllll}\mathrm{C}: 58 & \mathrm{R}: 105 & \mathrm{C}: 61 & \mathrm{R}: 134 & \mathrm{C}: 0 & \mathrm{R}: 251 \\ \mathrm{M}: 100 & \mathrm{G}: 21 & \mathrm{M}: 32 & \mathrm{G}: 148 & \mathrm{M}: 43 & \mathrm{G}: 176 \\ \mathrm{Y}: 51 & \mathrm{~B}: 79 & \mathrm{Y}: 94 & \mathrm{~B}: 63 & \mathrm{Y}: 85 & \mathrm{~B}: 59 \\ \mathrm{~K}: 12 & & \mathrm{~K}: 0 & & \mathrm{~K}: 0 & \\ & & & & \\ \text { PANTONE \# } \mathrm{P} 85-8 \mathrm{C} & \text { PANTONE \# P 161-15C } & \text { PANTONE \# 129 U }\end{array}$

Figura 8: Composición de colores de logotipo Señora Chicha. Elaboración propia.

\section{Análisis visual}

Personalidad que transmite cada logo en comparación con la competencia:
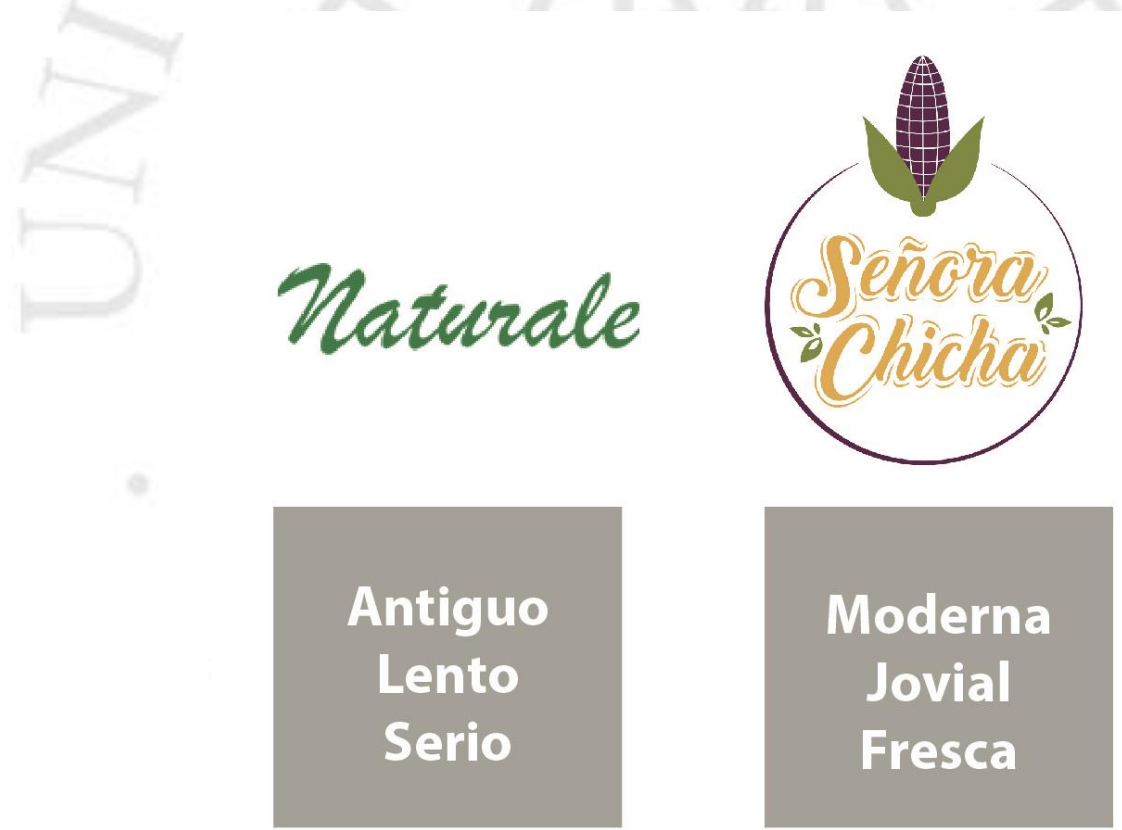

Figura 9: Personalidad de marcas. Elaboración propia.

\section{Slogan}

La frase que acompañará a la marca será "Lo hace natural", de esta manera se estaría cumpliendo uno de los atributos principales: sin azúcar, sin preservantes, sin colorantes. Además, como se mencionó previamente, la marca alude a una experta, por ende en el slogan recordamos que Señora Chicha sabe prepararla natural. 
Back to black

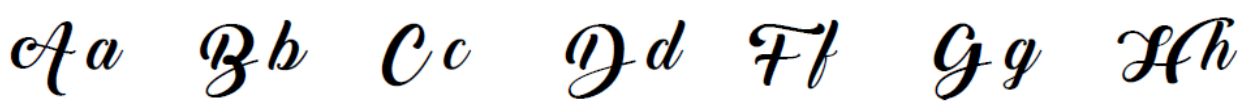

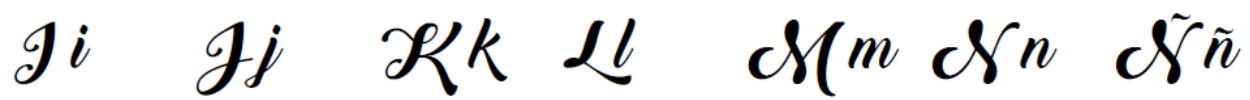

Oa Pp Qq Rr Sr Tt $\mathcal{U}$

Viv 2 w $x$ yy

Figura 10: Detalle de tipografía de logotipo Señora Chicha. Elaboración propia.

\subsubsection{Packing}

\section{Etiqueta}

En cuanto a la etiqueta se propone una troquelada donde destaque la forma del isotipo, el fondo es color blanco humo y se le han colocado líneas curvas que generan textura y le dan movilidad al diseño. También contiene información relevante sobre la marca, donde por un lado se recuerda qué es señora chicha y los ingredientes naturales que la componen. Partiendo del conocimiento que las amas de casa modernas tienen la cultura de leer la información de los productos que compran, se consideró conveniente no utilizar el típico sello en la parte frontal del etiquetado indicando el principal atributo, ya que rompería con la estética propuesta invadiendo el logo.

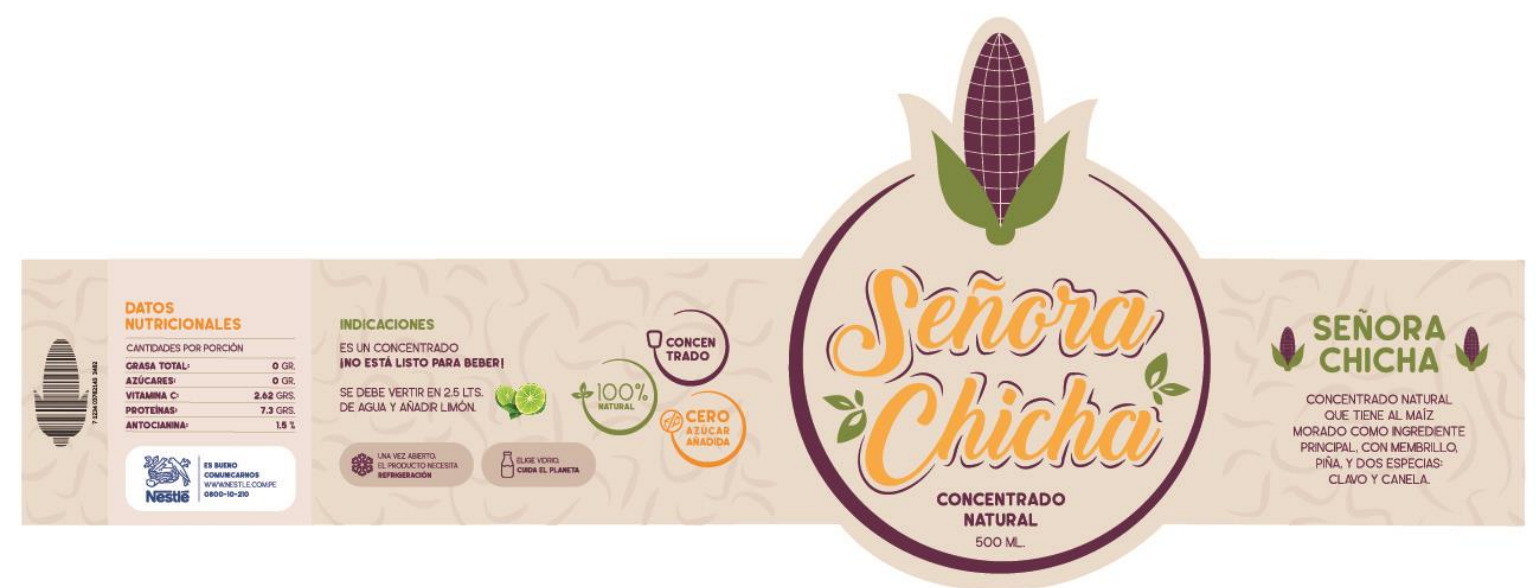


Es así que se colocó en uno de los lados los 3 principales atributos, una indicación respecto al "uso de limón al gusto" y la tabla nutricional.

Se ha considerado una fuente secundaria como parte de la identidad gráfica de la marca para uso en la etiqueta y piezas digitales:

\section{LEONARDO ROUNDED}

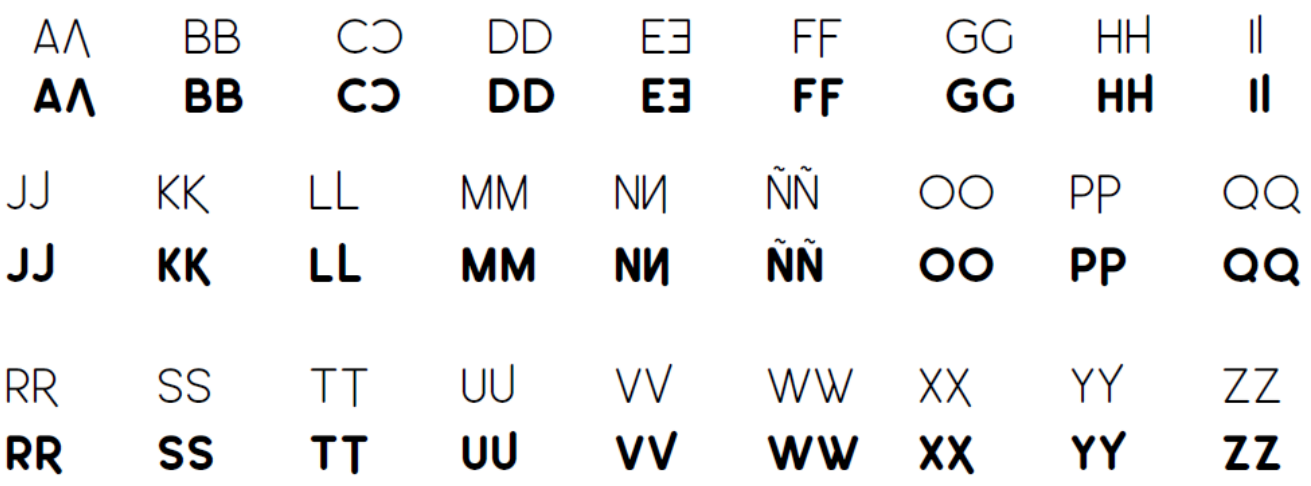

Figura 11: Detalle de tipografía secundaria. Elaboración propia.

\section{Presentación}

La presentación elegida es una botella de vidrio transparente de 500ml. Resulta muy importante que la etiqueta no cubra el total de la botella para que pueda verse el color del líquido al interior. Además, el recurso del vidrio apela a una cultura de protección del medio ambiente y por sus propias características conserva mejor el contenido que una botella de plástico. La chapa para esta presentación es metálica de tipo rosca y refuerza el mensaje de la marca.

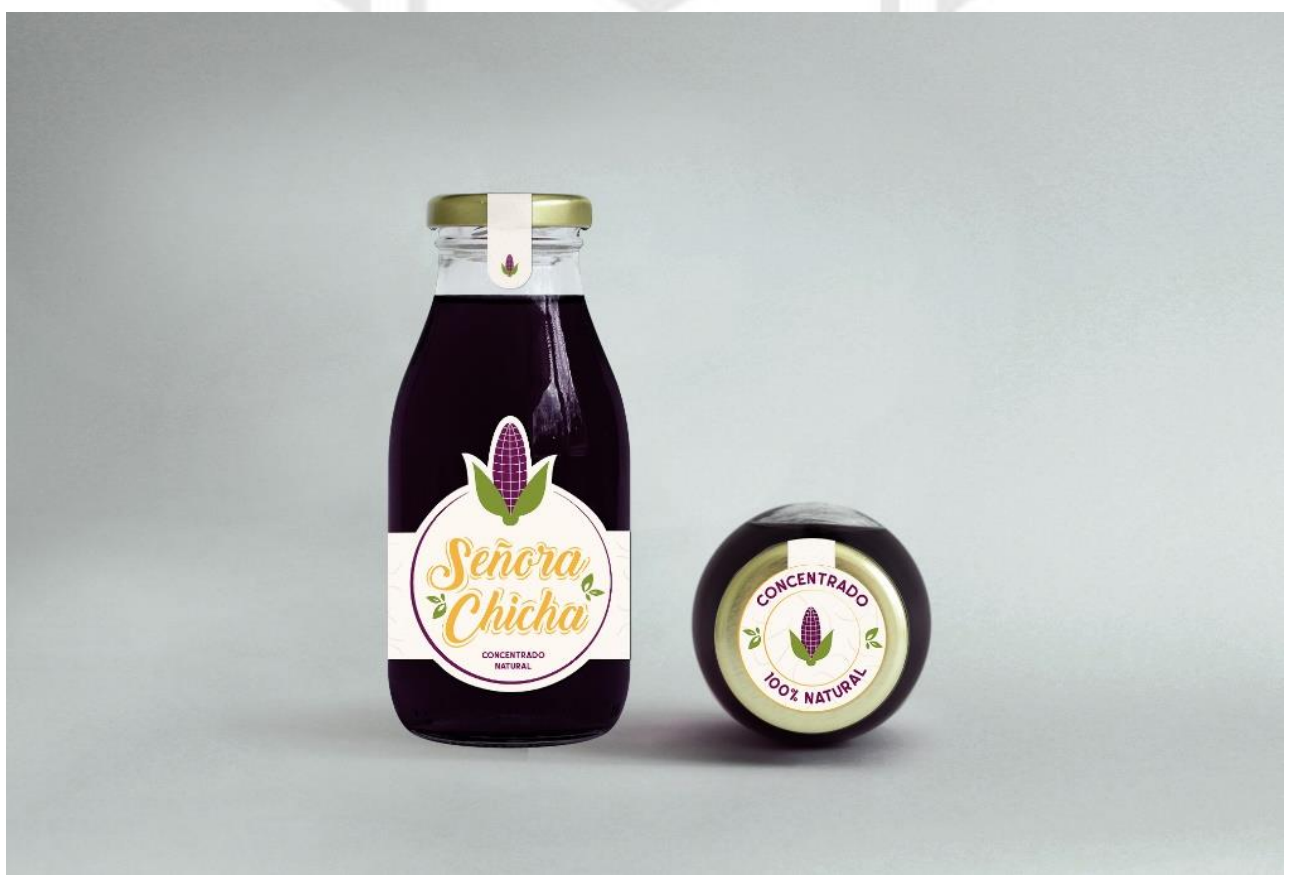




\section{CAPÍTULO IV \\ LA CAMPAÑA Y OBJETIVOS DE MARKETING}

\subsection{Objetivos de marketing}

Para definir los objetivos de marketing del lanzamiento de Señora Chicha hay que tener presente que se trata de una marca de una empresa de grandes dimensiones en Perú como lo es Nestlé:

- Generar un alto nivel de notoriedad y reconocimiento de la marca en el plazo de 3 meses.

- Convertirnos en la marca preferida por las amas de casa dentro de la categoría durante el primer año de presencia en el mercado.

- Impulsar la comercialización en etapa de introducción (precio, promoción, distribución).

\subsection{Descripción de la campaña}

La campaña de lanzamiento concentrará sus esfuerzos en una etapa inicial en Lima Metropolitana y será lanzada en el mes de enero, aprovechando la época del verano e incremento del calor en la capital. Un punto a favor es el aumento del consumo de bebidas en esta temporada. La campaña tendrá un plazo de duración de 3 meses.

Se han dividido las acciones en dos momentos:

Etapa de intriga: se buscará generar curiosidad a través de influencers con menciones pagadas y espontáneas durante 1 semana con el objetivo de generar conversaciones al respecto en las redes sociales. También se aplicará una estrategia de marketing de contenido con material producido por la marca y a su vez con apoyo de notas patrocinadas, buscando brindarle información relevante al target. A estas acciones se le suma una importante inyección en digital (search y display) que acompañara a lo largo de los 3 meses.

Etapa de lanzamiento: al cabo de esta semana inicial de intriga, se desplegará la pauta en televisión y radio, también se contratará el servicio de publicidad exterior (out of home), y se realizarán activaciones en algunas zonas identificadas de Lima y también en establecimiento en ruta hacia la Panamericana, por la concurrencia a las playas durante la época del verano. 


\section{CAPÍTULO VII \\ ESTRATEGIA DE MEDIOS Y OBJETIVOS DE COMUNICACIÓN}

\subsection{Objetivo de Comunicación}

Los objetivos de comunicación son los siguientes:

- Dar a conocer los principales atributos de la marca durante el periodo de lanzamiento.

- Conectar emocionalmente con el público objetivo dando a conocer la propuesta de valor de la marca.

\subsection{ATL}

\subsubsection{Televisión}

Como se mencionó previamente, nuestro público objetivo son amas de casa modernas y con un perfil orientado hacia lo digital, por lo general no tienen tiempo para ver televisión de manera frecuente. Sin embargo al tratarse del lanzamiento de un producto con mucho potencial y anclado en la marca Nestlé, se consideró necesario destinar una parte del presupuesto en televisión.

La pauta se divide entre los canales con mayor audiencia en señal abierta, en su mayoría en horario nocturno y principalmente en programas noticiosos y de entretenimiento donde de esta manera. Cabe resaltar que los canales propuestos son los que tienen el mayor share de audiencia con públicos más estables.

\section{América TV:}

Primera Edición

América Noticias

De Vuelta al Barrio

El Artista del Año

Mi mamá cocina mejor que la tuya

Cuarto poder

\section{Frecuencia Latina:}

90 central

Amor de familia

Yo soy 
Andina (ATV):

Magaly TV La Firme

Día D

Nunca más

Gran Premier

\section{Concepto del spot:}

El spot propuesto busca mostrar al ama de casa que se acerque más con el perfil moderno, una ama de casa sin delantal. Se muestran tres situaciones de consumo del concentrado de chicha morada en donde encontramos a una mujer en roles diferentes, multifacética como es:

1. Regresando de hacer deporte busca algo refrescante y bebe un vaso de chicha del concentrado ya preparado. Con esta escena se busca reforzar el diferencial principal "sin azúcar añadida"

2. Un almuerzo familiar / reunión de amigos donde participan personajes de todas las edades. Reforzamos así las ideas de: rendidora ("LA" Señora Chicha), rápida y práctica de preparar y sobretodo que te saca de apuros.

3. La última situación muestra al ama de casa con saco, regresando de la oficina junto con su pequeño hijo añadiendo limón a la jarra con concentrado de Señora Chicha. Esta escena te sugiere que es natural, (sólo tienes que agregarle limón), también presenta el consumo apto para niños, y además muestra un rol más de la mujer moderna. 

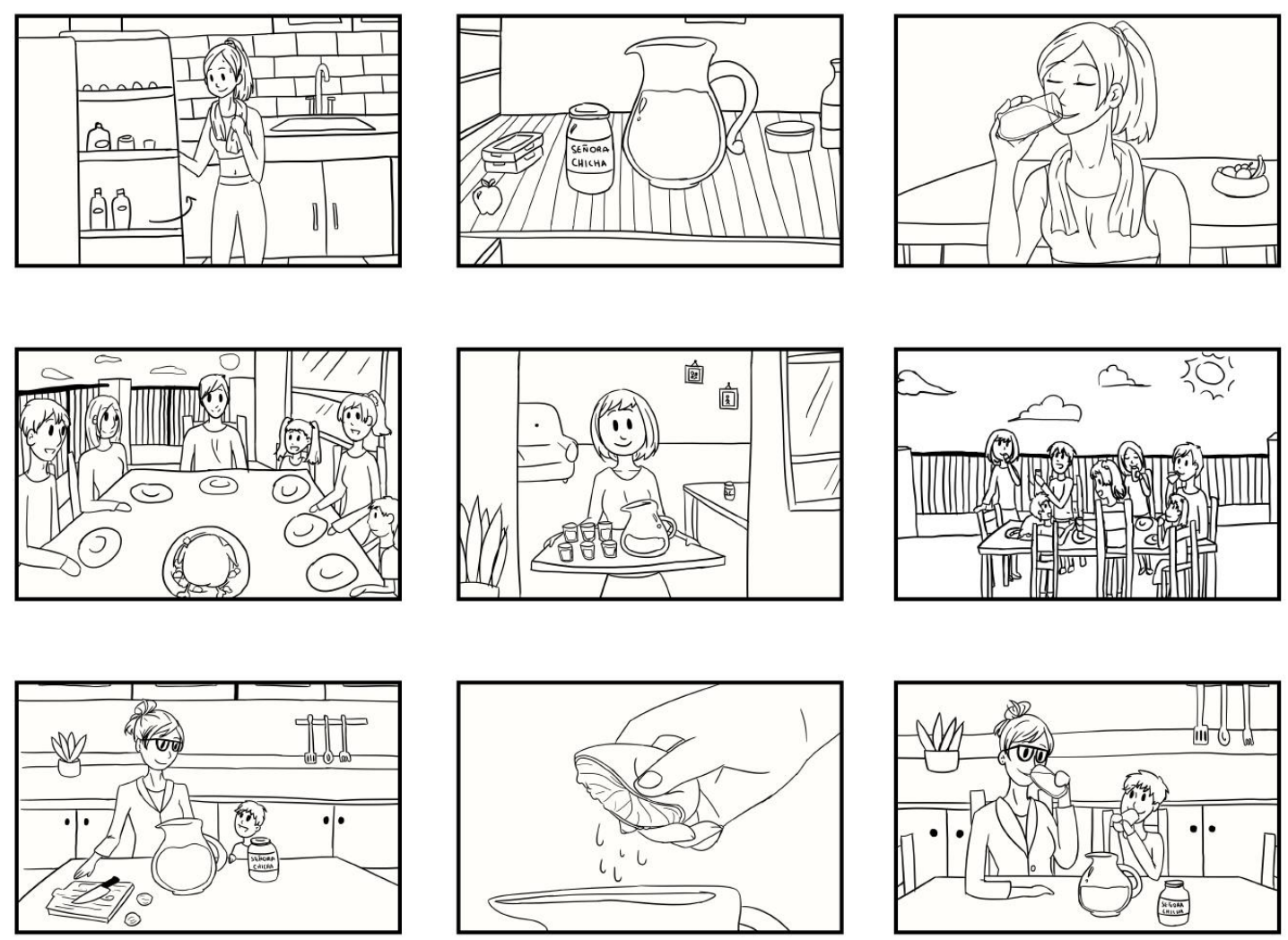

Ilustración 1: Planos de comercial para televisión.

\subsubsection{Radio}

El target se moviliza constantemente en auto propio y taxis donde escuchan radio mientras realizan sus múltiples actividades, pero también hay que recordar que tenemos en el target a las amas de casa que trabajan de manera independiente y tienen una rutina más flexible para acceder a la radio. Por su alcance y afinidad se delimitó la pauta de la siguiente manera:

- Radio Oxígeno: 8 avisos diarios de 20"de lunes a viernes.

- Radio RRP: 6 avisos diarios de 20" de lunes a viernes.

- Radio Felicidad: 8 avisos diarios de 20"de lunes a viernes.

- Radio Corazón: 8 avisos diarios de 20”de lunes a viernes.

\subsubsection{Revistas}

\section{$1 / 2$ página vertical en Revista Trome Más Mujer:}

Se ha planeado publicitar en 2 ocasiones en este medio ya que el índice de lectoría es del $30 \%$ en el sector $\mathrm{C}$ donde también se encuentra nuestro público objetivo. 


\section{1/2 página en Revista Somos:}

La Revista Somos tiene un alto índice de lectoría en su versión impresa, también cuentan con una versión digital. Este medio es bastante aceptado en los hogares peruanos y contiene información variada que nos permite tener mayor alcance.

\subsection{O.O.H}

Durante los meses que dura la campaña, estaremos en pantallas digitales que nos permitan cubrir las zonas más importantes de Lima, las cuales irán mostrando el material producido:

- Av. Universitaria / Av. La Marina, San Miguel

- Av. Primavera Cdra. 8, San Borja

- Av. Benavides / Cerro Verde, Surco
21,936,856 impactos mensual $14,118,979$ impactos mensual $28,905,238$ impactos mensual

En cada una de ellas se mostrarán las situaciones planteadas en el spot de televisión, de tal manera que se siga la misma línea conductora del mensaje sobre los diversos roles de la nueva ama de casa y sus situaciones de consumo de chicha:

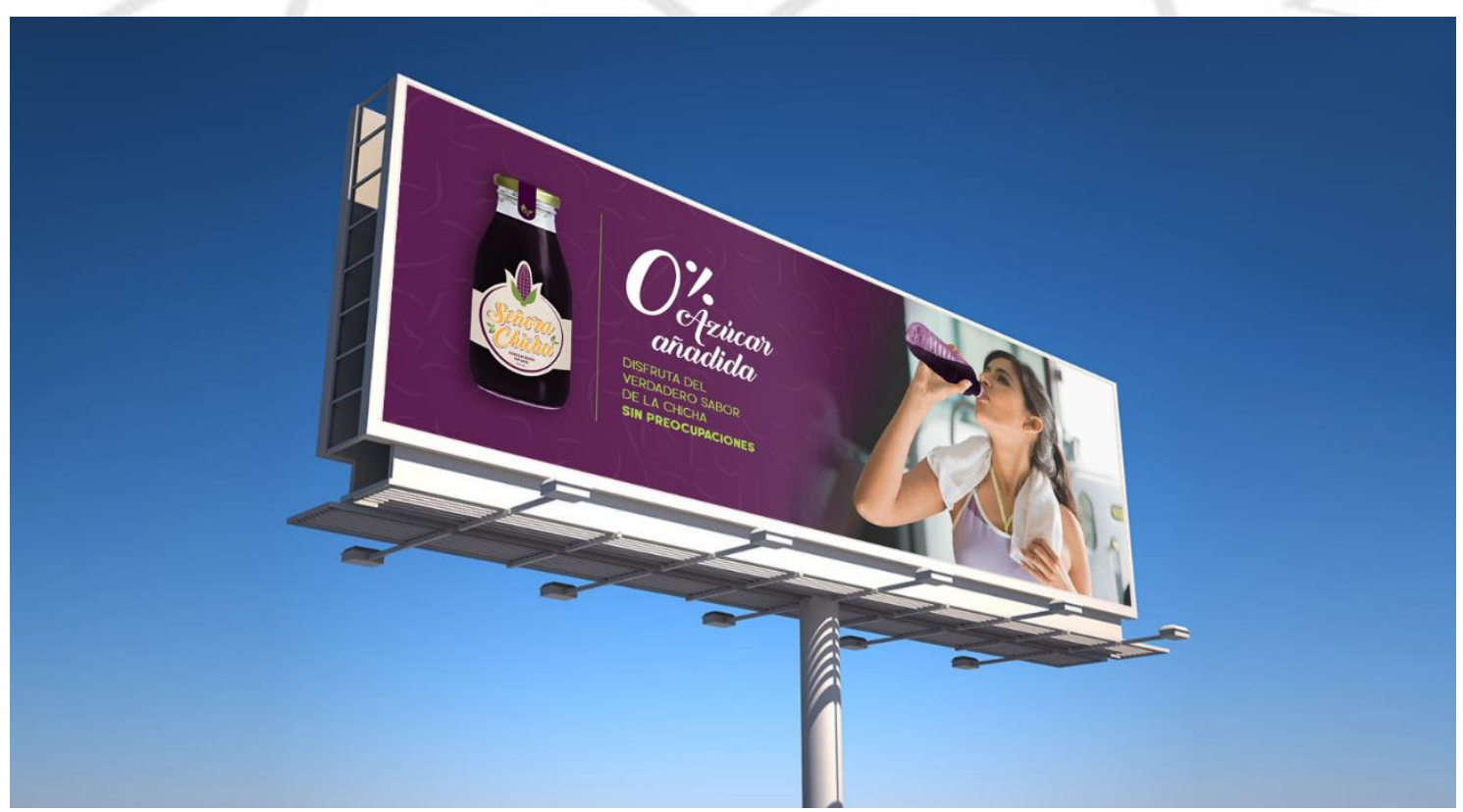

Ilustración 2: Pantalla digital O.O.H.

\subsection{Indoor}

El siguiente medio al cual está destinado un porcentaje de inversión a publicidad al interior de los centros comerciales porque es un lugar que atrae ampliamente al público objetivo en diversos momentos del día y situaciones, hay circulación de personas constantemente. Para este fin se han 
escogido tres establecimientos comerciales de mucha afluencia en zonas opuestas de la ciudad donde encontramos los diferentes NSE. El soporte para la publicidad son las escaleras eléctricas:

- Real Plaza Salaverry

- $\quad$ Real Plaza Primavera

- La Rambla Breña

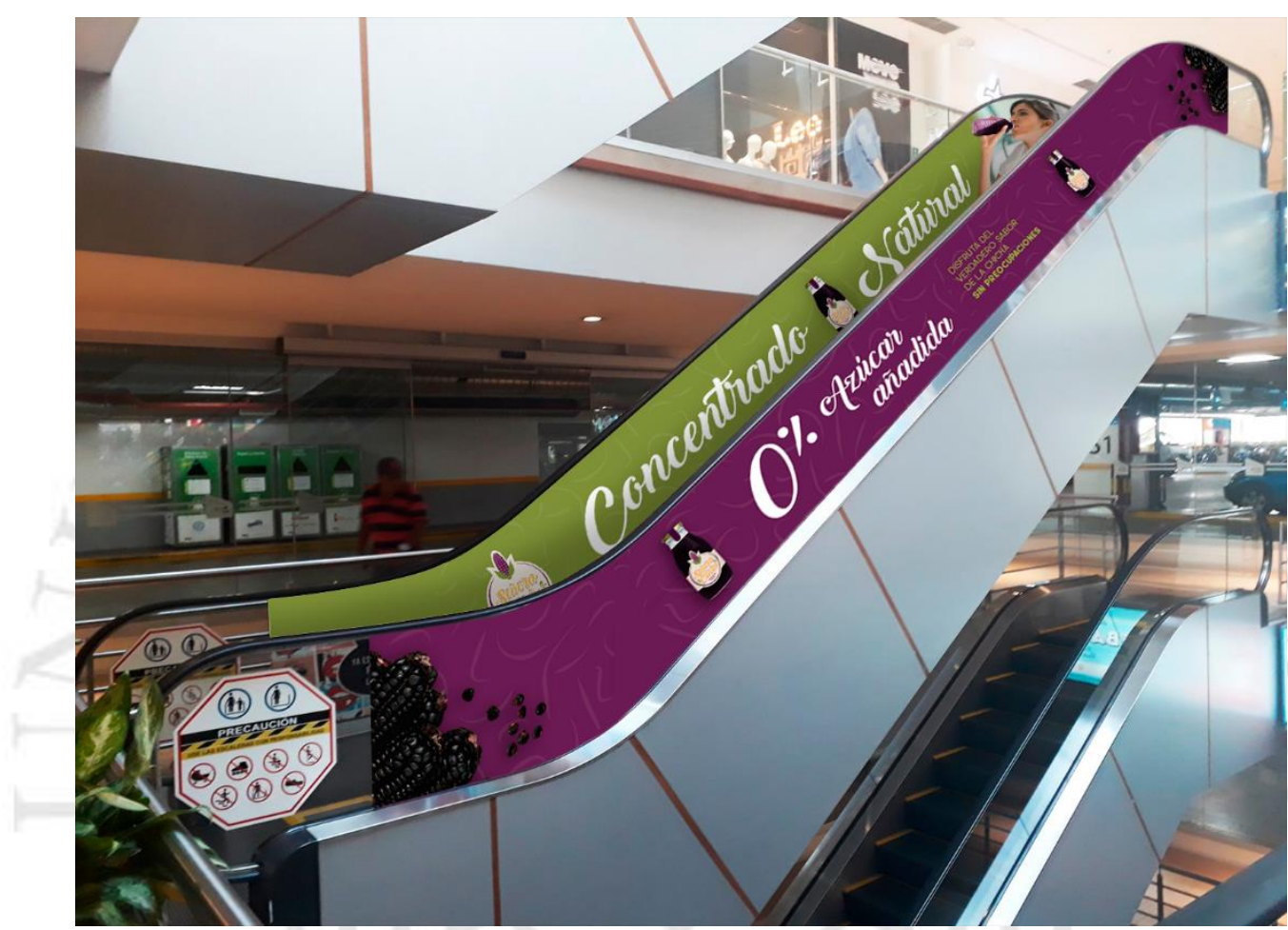

Ilustración 3: Escaleras brandeadas Indoor.

\subsection{Digital}

La estrategia planteada en digital es bastante potente pues es donde se genera el mayor contacto con el público objetivo a un costo menor:

\subsubsection{Redes sociales}

Se invertirá en pauta principalmente para Facebook e Instagram por ser las más populares y utilizadas en el público objetivo. Inicialmente se abrirán los perfiles manejando 3 categorías de contenido con los siguientes objetivos: 


\begin{tabular}{|c|c|c|}
\hline Categoría & Objetivo & Contenido \\
\hline Señora Chicha & Brand awareness & $\begin{array}{c}\text { Atributo principal de la marca, personalidad, } \\
\text { conocimiento sobre origen natural. }\end{array}$ \\
\hline Videos de recetas & Engagement & $\begin{array}{c}\text { Brindarle videos sobre recetas de platos } \\
\text { saludables y ricos. Los videos deben brindarle } \\
\text { información que colabore facilitándoles el día } \\
\text { a día pero finaliza con la frase "acompáñalo } \\
\text { con un rico vaso de Señora Chicha". }\end{array}$ \\
\hline Promoción & Ventas & $\begin{array}{c}\text { Informar sobre el precio, activaciones en la } \\
\text { ruta hacia las playas de Lima, y puntos de } \\
\text { venta donde pueden encontrar el producto. }\end{array}$ \\
\hline
\end{tabular}

Durante las primeras semanas se compartirán post con imágenes que respondan a brindar conocimiento del producto, estarán pauteados y se utilizarán call to action para que las seguidoras interactúen con las publicaciones, las mismas que se realizarán 4 días a la semana por la mañana y tarde. En el caso puntual de Instagram se pauteará más en las stories que en las publicaciones, en esta red se promoverán los siguientes hashtags: \#señorachicha \#chichaceroazucar

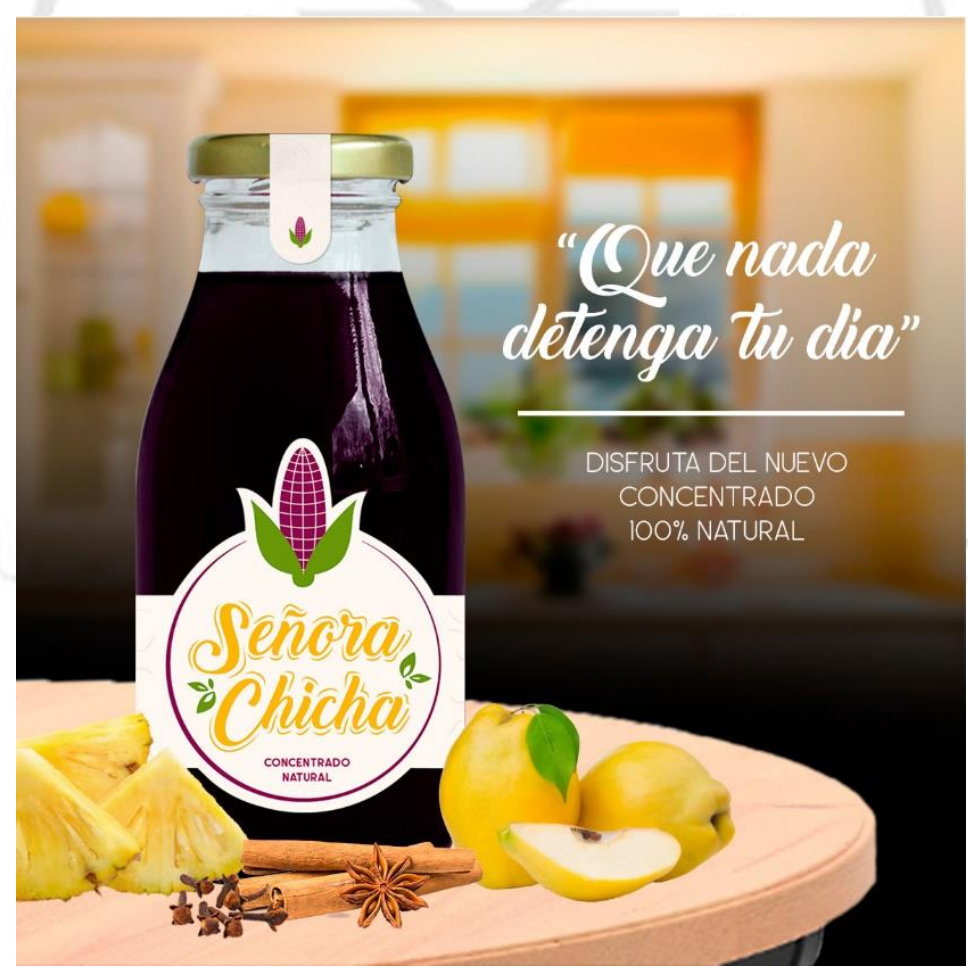




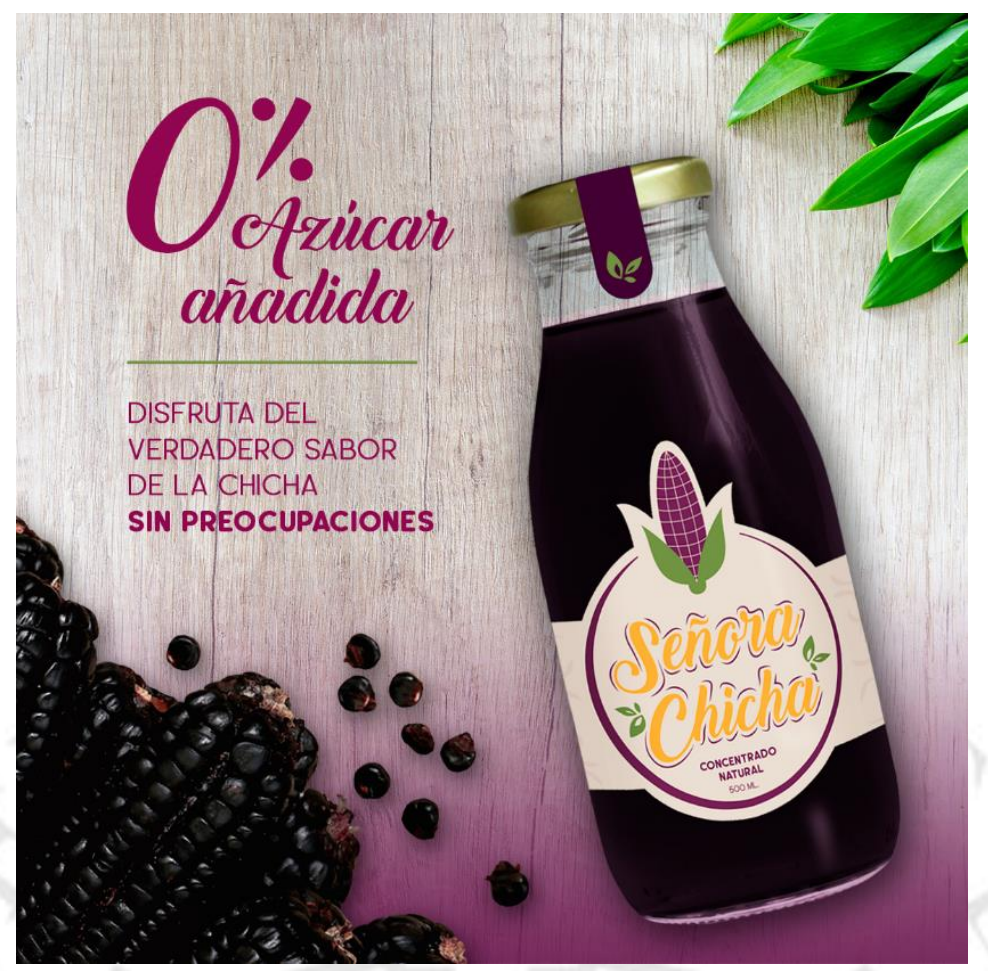

Durante el segundo mes de la campaña, se lanzará un concurso tanto en Facebook como Instagram para generar más interacción con el público objetivo. El concepto de este concurso será el descanso, partiendo de la idea que estas amas de casa no paran durante el día, entre cuidar de su familia, ocuparse del hogar, las tensiones laborales y además las actividades extra de crecimiento personal Señora Chicha las reconocerá con unas merecidas vacaciones. Pero como la familia es importante para ellas se ha buscado un lugar que cumpla con la experiencia completa para ellas, en tal sentido se ha elegido el Hotel Las Dunas en Ica, ya que está posicionado como el mejor hotel para familias, cuenta con actividades para grandes y chicos, y lo más importante es que no implica invertir tiempo en vuelos ya que su cercanía permite que disfruten de un fin de semana diferente.

\subsubsection{Google Display}

Se buscará estar presente en aquellas búsquedas directas a la oportunidad comercial de Señora Chicha con anuncios enfocados al perfil en formato rich media, distribuyendo la pauta con videos de recetas de platos saludables para así captar la atención. 
Ejemplo de anuncio rich media en Google Display:

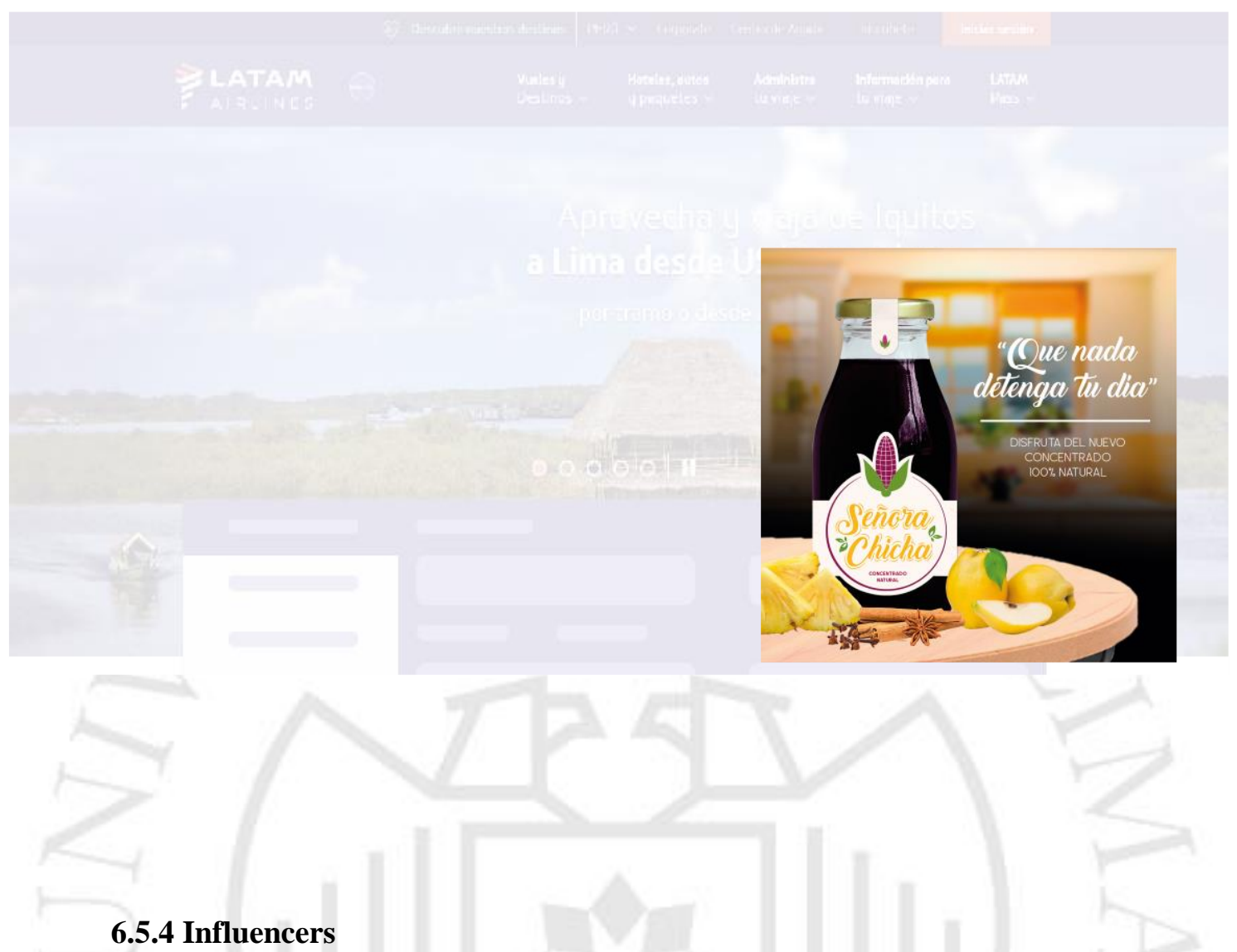

Por el tipo de contenido que comparten y el estilo que presentan en sus redes se propone trabajar menciones pagadas con Maria Paz Gonzáles Vigil (@mariapazgvb) y a María Pía Copello (@ piacopello). Día a día los perfiles seleccionados no sólo comparten las actividades con sus hijos sino las laborales, se muestran activas y preocupadas por sus familias. En el caso de María Pia Copello tiene un canal en YouTube donde comparte en la mayoría de ocasiones recetas y tips de cocina lo cual significa un plus para la marca.

Además de tenerlas como principales embajadoras del mensaje, durante el desarrollo de la campaña se enviarán presentes a 10 influencers adicionales. El obsequio está alineado al mensaje de la marca: un pack de agenda y organizador personalizado con sus nombres, por supuesto el obsequio incluye la presentación de Señora Chicha para que puedan mostrarla y probarla.

Los perfiles seleccionados y justificación son los siguientes:

1. Emilia Drago: es actriz y bailarina conocida, tiene un estilo de vida familiar y es mama primeriza de una niña pequeña.

2. After Parto: nació en las redes, es ágil y natural, mama de mellizas y de una niña de 5 años, es emprendedora y se muestra siempre en múltiples actividades. 
3. Sophie Crown: es una marca de joyas que vende sus productos a través de mensajes empoderadores, pero más importante aún es que la dueña y fundadora también comparte su día a día como madre y emprendedora.

4. Papis por primera vez: es una cuenta de padres jóvenes primerizos, ellos comentar diariamente sus experiencias y tips para viajes y actividades con sus hijos.

5. Solange Martínez: es la fundadora de Armónica Café, la popular cafetería de comida saludable. Se propone de manera clave ya que además de comentar eventos sociales a los que acude, gran parte de su contenido está orientado a la alimentación saludable.

6. Thalia Echecopar: es una fashion blogger, que brinda contenido de moda y estilo a nuestro público objetivo. Tiene una marca de ropa y como plus adicional, acaba de ser mamá.

7. Ximena Llosa: tiene un programa en cable, es chef y constantemente muestra recetas y acompañamientos para sus platos.

8. Connie Chaparro: popular actriz, conductora de radio y mama muy bien posicionada en el público objetivo por sus post acerca de su rol de madre.

9. La Vida en Serendipity: fue una de las primeras mamás blogueras en salir a la luz, tiene un importante público cautivo y además aporta con tips de moda, estilo, y otros temas de interés.

10. Karen Schwarz: desde que se convirtió en mamá, la conductora comparte contenido de vida familiar, tips de alimentación, y sus multiples actividades como figura de marcas.

\subsection{Activaciones}

Al tratarse de una bebida que promete el sabor único de la chicha hecha en casa, resulta importante que el público objetivo lo compruebe, es por eso que se han desarrollado una serie de activaciones en diversos puntos.

\subsubsection{Mercados tradicionales}

Tal como se mencionó en el inicio de este informe, los mercados tradicionales, sobretodo los ubicados en las zonas de NSE C venden chicha morada casera lista. Por ello se ha visto conveniente realizar visitas a los mercados más representativos de distritos como Santa Anita y Los Olivos.

Durante la mañana de fines de semana, se acudirá a estos mercados junto con una impulsadora que repartirá un recetario de tipo fascículo encuadernado, práctico de guardar y moderno. Las recetas serán bastante novedosas y sobretodo nutritivo, como por ejemplo: hamburguesas de 
lentejas, postres a base avena, entre otras, por supuesto que en cada una se tendrá presente el acompañamiento de Señora Chicha.

\subsubsection{Supermercados}

Se tendrán góndolas brandeadas con la marca en los principales supermercados de la ciudad en zonas de NSE AB. Las activaciones estarán dirigida hacia los sentidos, esto se logrará apelando al olor típico que se desprende de la chicha hecha en casa. La idea es que en el pasillo correspondiente a bebidas se perciba el olorcito a chicha morada para sugerir la naturalidad del producto.
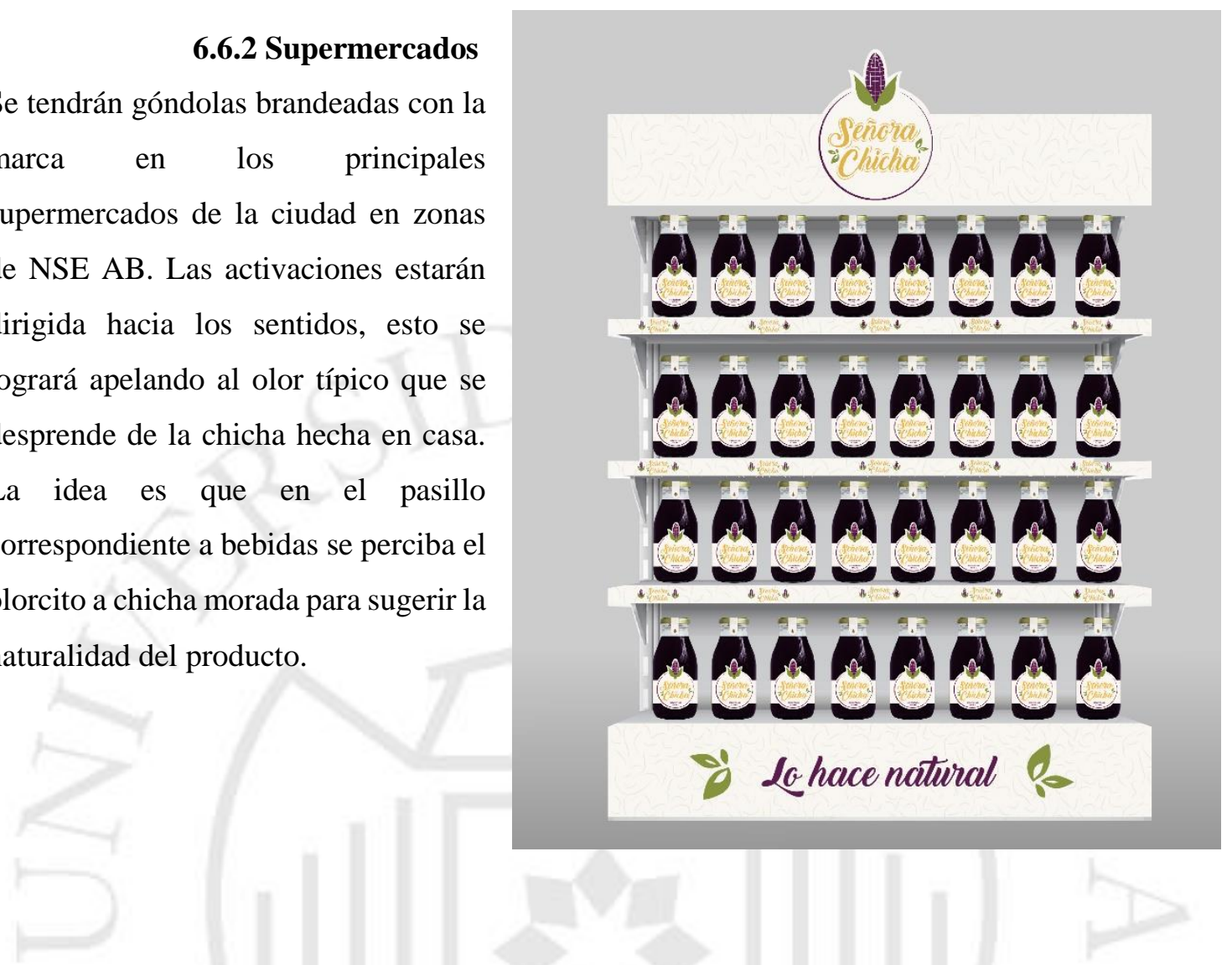

\subsubsection{Estaciones de Servicio}

Tal como se precisó, la campaña de lanzamiento tendrá lugar en los meses de verano, por ello se busca complementar la comunicación en la valla carretera hacia las playas del sur con activaciones en las tiendas Viva de la estación de servicio PECSA antes del peaje, y PECSA Punta Hermosa.

Lo que se busca es estar presente donde está el público objetivo, en verano hay mucha afluencia en el sur de Lima y por lo general las tiendas de conveniencia de las estaciones de servicio son el punto perfecto para sugerir la compra.

Se tendrán anfitrionas en las tiendas mencionadas ofreciendo degustaciones a las personas que hacen un alto para hacer las últimas compras de su día playero. Es importante también tener identificado estos puntos con jalavistas troquelados: 

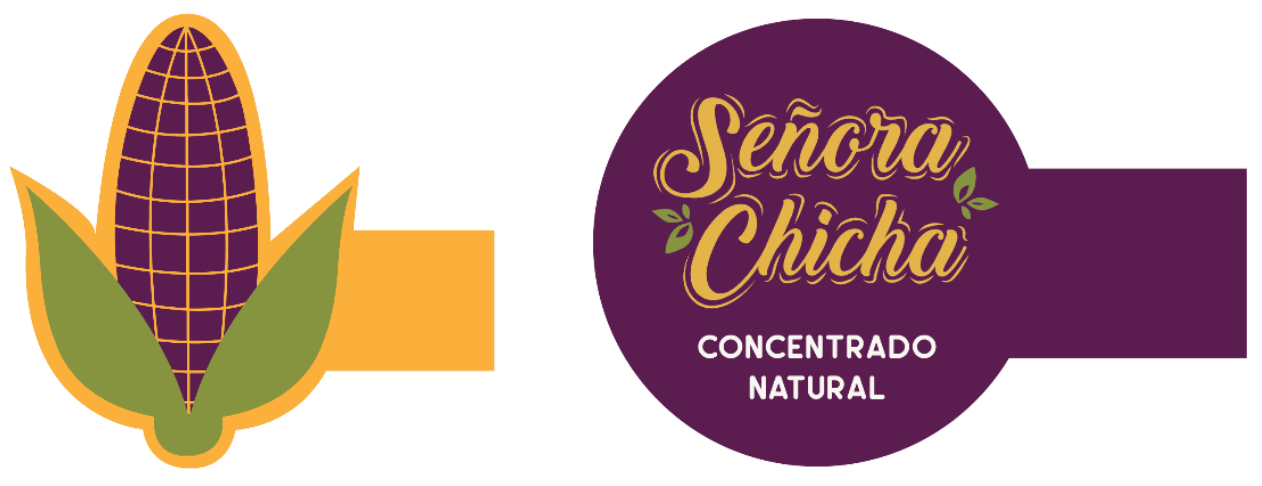

\subsubsection{Casa Nestlé}

Casa Nestlé es un espacio de la empresa ubicado en San Isidro que realiza iniciativas de alimentación y nutrición. También se realizan talleres y clase de cocina que son comunicados a la base de datos de Nestlé Perú. Por ello, incluir a la nueva marca Señora Chicha como "auspiciadora" del taller sería de alto impacto.

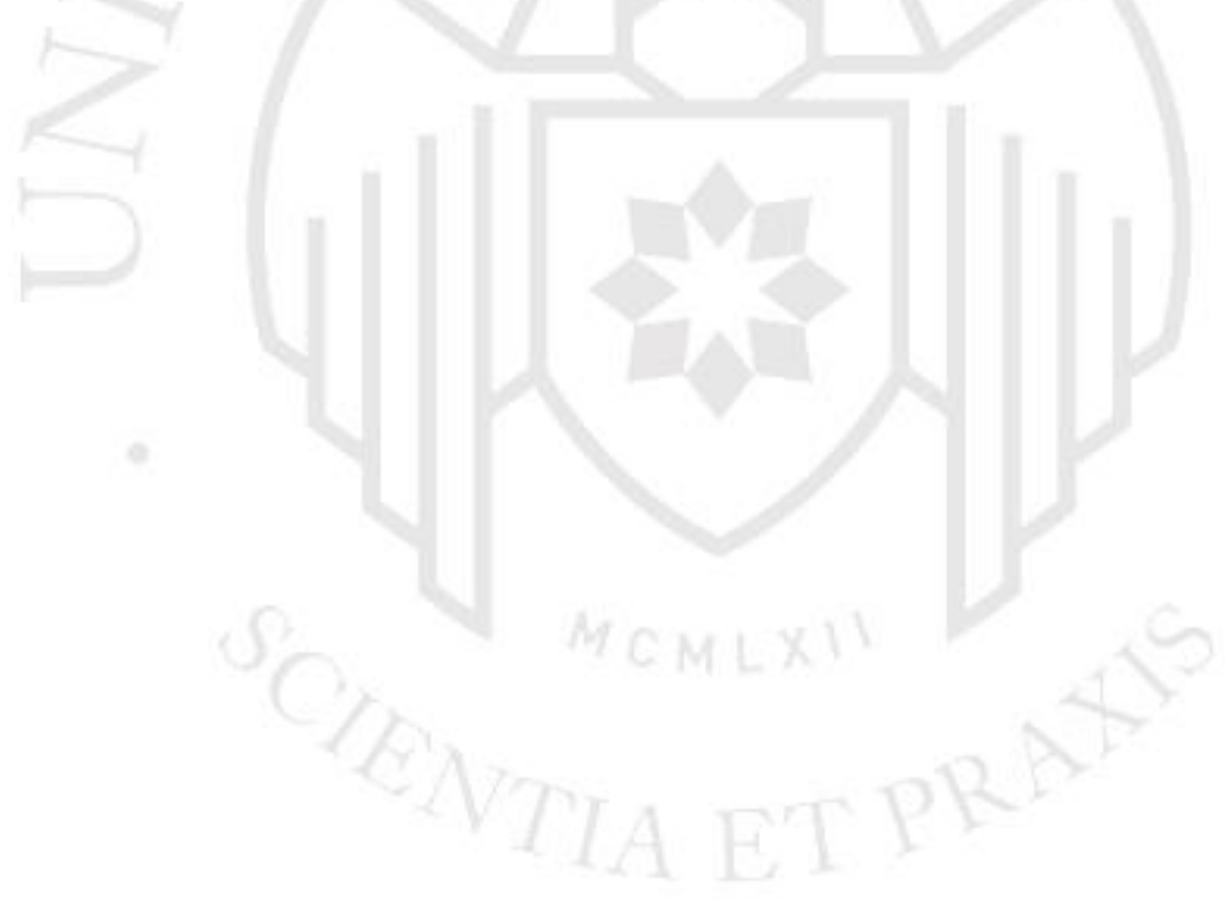




\section{CAPÍTULO VII PRESUPUESTO}

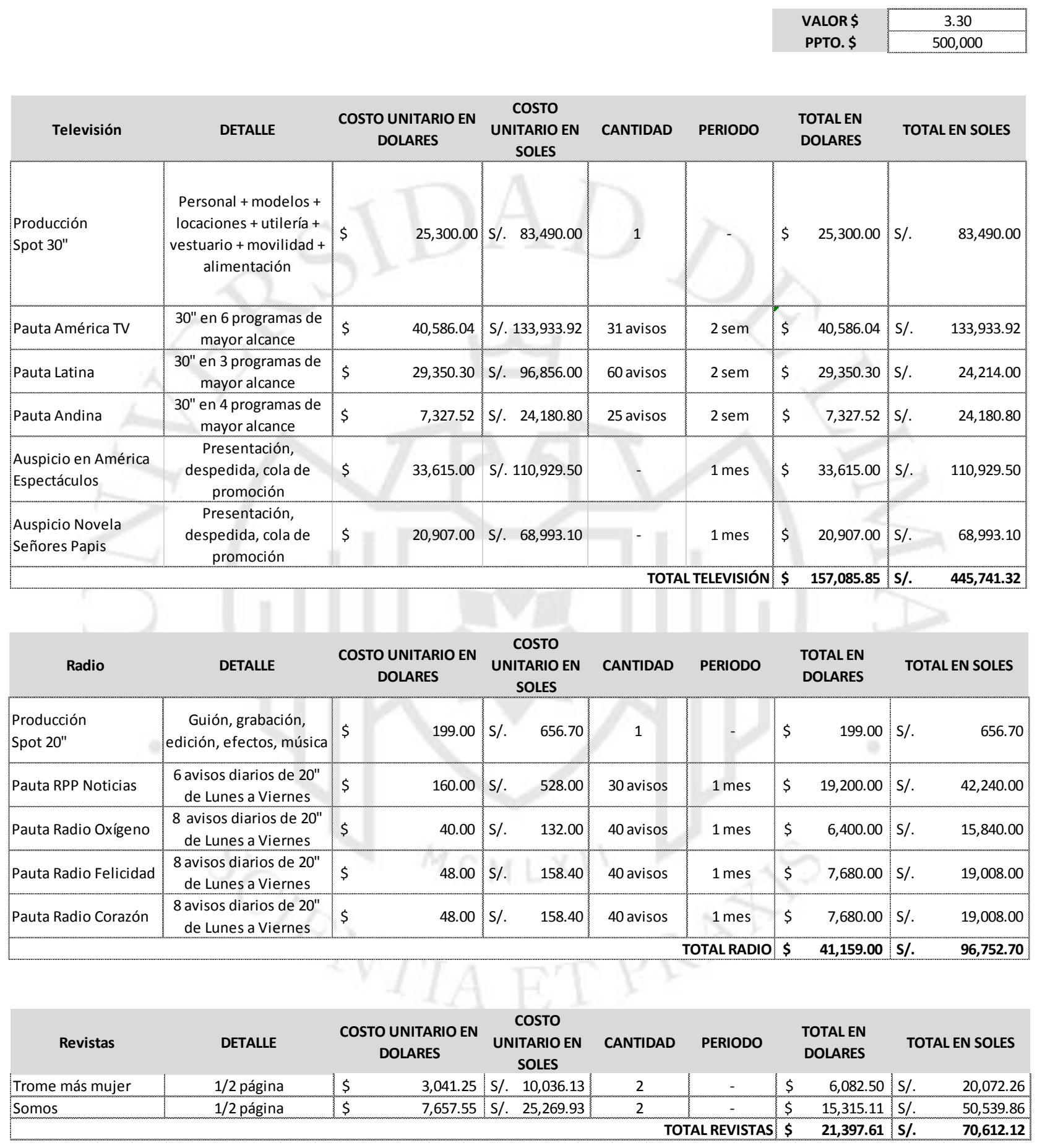




\begin{tabular}{|c|c|c|c|c|c|c|c|c|c|}
\hline O.O.H & DETALLE & $\begin{array}{l}\text { COSTO UNITARIO EN } \\
\text { DOLARES }\end{array}$ & $\begin{array}{l}\text { COSTO } \\
\text { UNITARIO EN } \\
\text { SOLES }\end{array}$ & CANTIDAD & PERIODO & & $\begin{array}{l}\text { TOTAL EN } \\
\text { DOLARES }\end{array}$ & \multicolumn{2}{|c|}{ TOTAL EN SOLES } \\
\hline $\begin{array}{l}\text { Pantallas dynamic } \\
\text { content }\end{array}$ & $\begin{array}{c}\text { Exposición de } 7 \\
\text { segundos cada un } \\
\text { minuto las } 24 \text { horas de } \\
\text { día. }\end{array}$ & $3,030.30$ & S/. $\quad 10,000.00$ & 3 & 3 & $\$$ & $27,272.73$ & $\mathrm{~S} / \mathrm{.}$ & $90,000.00$ \\
\hline $\begin{array}{l}\text { Alquiler de panel en } \\
\text { carretera }\end{array}$ & $\begin{array}{c}\text { Ubicado en la } \\
\text { panamericana sur } \\
\text { durante la temporada } \\
\text { de playa (Costo por } \\
\text { total temporada) }\end{array}$ & $7,575.76$ & S/. $25,000.00$ & 1 & 3 meses & $\$$ & $7,575.76$ & $\mathrm{~S} / \mathrm{.}$ & $25,000.00$ \\
\hline \multicolumn{6}{|r|}{ TOTAL O.O.H } & $\$$ & $34,848.48$ & S/. & $115,000.00$ \\
\hline
\end{tabular}

\begin{tabular}{|c|c|c|c|c|c|c|c|c|c|}
\hline INDOOR & DETALLE & $\begin{array}{c}\text { COSTO UNITARIO EN } \\
\text { DOLARES }\end{array}$ & $\begin{array}{l}\text { COSTO } \\
\text { UNITARIO EN } \\
\text { SOLES }\end{array}$ & CANTIDAD & PERIODO & & $\begin{array}{l}\text { TOTAL EN } \\
\text { DOLARES }\end{array}$ & \multicolumn{2}{|c|}{ TOTAL EN SOLES } \\
\hline Escaleras eléctricas & $\begin{array}{c}\text { Real plaza Salaverry, } \\
\text { Real plaza Primavera, La } \\
\text { Rambla Breña }\end{array}$ & $7,000.00$ & S/. $21,000.00$ & 3 & 1 mes & $\$$ & $21,000.00$ & S/. & $63,000.00$ \\
\hline \multicolumn{6}{|c|}{ TOTAL INDOOR } & $\$$ & $21,000.00$ & S/. & $63,000.00$ \\
\hline
\end{tabular}

\begin{tabular}{|c|c|c|c|c|c|c|c|c|c|c|}
\hline Digital & DETALLE & & $\begin{array}{l}\text { ITARIO EN } \\
\text { ARES }\end{array}$ & $\begin{array}{l}\text { COSTO } \\
\text { UNITARIO EN } \\
\text { SOLES }\end{array}$ & CANTIDAD & PERIODO & & $\begin{array}{l}\text { OTAL EN } \\
\text { OLARES }\end{array}$ & TOTAL & EN SOLES \\
\hline $\begin{array}{l}\text { Diseño de piezas } \\
\text { gráficas }\end{array}$ & $\begin{array}{c}4 \text { formatos para redes y } \\
5 \text { formatos para Google } \\
\text { Display }\end{array}$ & $\$$ & 620.00 & S/. $\quad 2,046.00$ & 9 piezas & - & $\$$ & 620.00 & S/. & $2,046.00$ \\
\hline $\begin{array}{l}\text { Videos cortos para } \\
\text { alimentar con } \\
\text { contenido dinámico } \\
\text { las redes }\end{array}$ & $\begin{array}{c}\text { Producción simple }+ \\
\text { animación }+ \\
\text { musicalización + edición }\end{array}$ & $\$$ & 484.85 & S/. $\quad 1,600.00$ & 6 & - & $\$$ & $2,909.09$ & S/. & $9,600.00$ \\
\hline $\begin{array}{l}\text { Inversión en pauta en } \\
\text { Facebook }\end{array}$ & Facebook & $\$$ & $2,500.00$ & S/. $\quad 8,250.00$ & - & 3 & $\$$ & $7,500.00$ & $\mathrm{~S} /$. & $24,750.00$ \\
\hline $\begin{array}{l}\text { Inversión en pauta en } \\
\text { Facebook }\end{array}$ & Instagram & $\$$ & $2,500.00$ & S/. $\quad 8,250.00$ & - & 3 & $\$$ & $7,500.00$ & S/. & $24,750.00$ \\
\hline $\begin{array}{l}\text { Inversión en pauta } \\
\text { Youtube }\end{array}$ & Youtube & $\$$ & $7,500.00$ & S/. $24,750.00$ & - & 3 & $\$$ & $22,500.00$ & S/. & $74,250.00$ \\
\hline $\begin{array}{l}\text { Inversión Google } \\
\text { Display }\end{array}$ & Google Display & $\$$ & $7,500.00$ & S/. $\quad 17,938.00$ & - & 3 & $\$$ & $22,500.00$ & S/. & $53,814.00$ \\
\hline $\begin{array}{l}\text { Landing Page y } \\
\text { dominio }\end{array}$ & $\begin{array}{l}\text { Landing page para info } \\
\text { de marca y concurso en } \\
\text { redes }\end{array}$ & $\$$ & $2,300.00$ & S/. $\quad 7,590.00$ & - & - & $\$$ & $2,300.00$ & S/. & $7,590.00$ \\
\hline $\begin{array}{l}\text { Premios para } \\
\text { concurso en redes }\end{array}$ & $\begin{array}{c}2 \text { Paquetes familiares } \\
\text { para fin de semana con } \\
\text { todo incluido en Hotel } \\
\text { Las Dunas }\end{array}$ & $\$$ & 788.18 & S/. $2,601.00$ & 2 & & $\$$ & $1,576.36$ & $\mathrm{~S} /$. & $5,202.00$ \\
\hline $\begin{array}{l}\text { Maria Paz GV, } \\
\text { Mariapia Copello }\end{array}$ & $\begin{array}{c}\text { Menciones posteadas } \\
\text { en stories y } \\
\text { publicaciones instagram }\end{array}$ & $\$$ & 606.06 & $2,000.00$ & 2 & 3 & $\$$ & $3,636.36$ & $\mathrm{~S} /$. & $12,000.00$ \\
\hline $\begin{array}{l}\text { Influencers de estilo } \\
\text { moda, fitness y } \\
\text { mamás blogueras } \\
\text { identificadas }\end{array}$ & \begin{tabular}{|} 
Pack de chicha morada + \\
agenda y organizadores \\
de La Papelerie \\
personalizados
\end{tabular} & $\$$ & 45.45 & 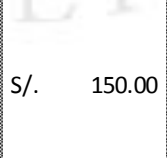 & 10 & - & $\$$ & 454.55 & $\mathrm{~S} /$. & $1,500.00$ \\
\hline \multicolumn{7}{|c|}{ TOTAL DIGITAL } & $\$$ & $71,496.36$ & S/. & $215,502.00$ \\
\hline
\end{tabular}




\begin{tabular}{|c|c|c|c|c|c|c|c|c|c|c|c|}
\hline Activaciones & DETALLE & & $\begin{array}{l}\text { ARIO EN } \\
\text { ES }\end{array}$ & $\begin{array}{r}\text { C } \\
\text { UNIT } \\
S \\
\end{array}$ & $\begin{array}{l}\text { OSTO } \\
\text { TARIO EN } \\
\text { OLES }\end{array}$ & CANTIDAD & PERIODO & & $\begin{array}{l}\text { TAL EN } \\
\text { JLARES }\end{array}$ & \multicolumn{2}{|c|}{ TOTAL EN SOLES } \\
\hline Recetarios & $\begin{array}{c}\text { Producción y } \\
\text { encuadernación }\end{array}$ & $\$$ & 0.33 & S/. & 1.10 & 30,000 & - & $\$$ & 9,995 & $\mathrm{~S} /$. & 32,982 \\
\hline Jalavistas & $\begin{array}{c}\text { Supermercados y } \\
\text { tiendas de conveniencia }\end{array}$ & $\$$ & 715.15 & S/. & $2,360.00$ & 1,460 & & $\$$ & 715.15 & S/. & 2,360 \\
\hline $\begin{array}{l}\text { Degustaciones en } \\
\text { edificios Co-working } \\
\text { (Comunal, Regus, We } \\
\text { Work) }\end{array}$ & Anfitriona + modulo & $\$$ & 681.82 & $\mathrm{~S} /$. & $2,250.00$ & & 3 & $\$$ & $2,250.00$ & $\$$ & 681.82 \\
\hline
\end{tabular}

\begin{tabular}{|l|lr|rr}
\hline SUB-TOTAL & $\$$ & $360,747.01$ & S/. & $1,044,590.14$ \\
\hline
\end{tabular}

\begin{tabular}{l|lr|rr} 
IGV & $\$$ & $64,934.46$ & $\mathrm{~S} /$. & $188,026.23$
\end{tabular}

\begin{tabular}{l|ll|ll|} 
TOTAL & $\$ 425,681.47$ & $\mathrm{~S} /$. & $1,232,616.37$
\end{tabular} 


\section{RECOMENDACIONES}

- La campaña de lanzamiento culmina fines de marzo, en tal sentido el periodo de mantenimiento abarcaría los meses de invierno donde se puede también empezar a comunicar otros modos de consumo del concentrado de chicha morada, por ejemplo para los postres tradicionales, siempre alineando el mensaje con los atributos principales.

- En digital, se recomienda utilizar la herramienta de Listening en social media, para monitorear que es lo que se dice de la marca en las conversaciones. Activarla no sólo nos permite obtener información relevante sino que también mantiene alerta en casos de crisis.

- Una vez establecida en el mercado y en top of mind del público objetivo, sería ideal completar el ecosistema digital de la marca creando un app que responda a todos los planteamientos sobre personalidad y ventajas. Por ejemplo un app dinámica sobre organización de tareas podría ser una opción. 


\section{REFERENCIAS}

- APEIM. (2019). Niveles socioeconómicos 2018. Recuperado del sitio de Internet de APEIM: http://www.apeim.com.pe/wp-content/themes/apeim/docs/nse/APEIM-NSE2018.pdf

- Arellano Marketing. (2019). Consumo Masivo. Obtenido de Arellano Marketing: https://www.arellano.pe/consumo-masivo/

- Arellano Marketing.(2019). Los seis estilos de vida. Obtenido de Arellano Marketing: https://www.arellano.pe/estilos-de-vida/

- CCL. (2019). Sube el costo de la canasta básica y aún no está del todo cubierta. Obtenido de la Cámara de Comercio de Lima: https://www.camaralima.org.pe/repositorioaps/0/0/par/r786_2/info_esp_786.pdf

- El Peruano. (2018). Decreto Supremo que aprueba el Reglamento de la Ley $N^{\circ} 30021$, Ley de Promoción de la Alimentación Saludable. Obtenido de El Peruano: https://busquedas.elperuano.pe/normaslegales/decreto-supremo-que-aprueba-elreglamento-de-la-ley-n-30021-decreto-supremo-n-017-2017-sa-1534348-4/

- El Comercio. (2017). INEI: “Más del 65\% de las madres en el Perú trabajan”. Obtenido de El Comercio: https://elcomercio.pe/lima/inei-65-madres-peru-420051

- Gestión. (2017). Lima Orgánica: "el mercado de comida saludable ha evolucionado favorablemente por la demanda del público". Obtenido de Diario Gestión: https://gestion.pe/tendencias/lima-organica-mercado-comida-saludable-evolucionadofavorablemente-demanda-publico-132445

- Gestión. (2017). ¿Cuántas horas al día pasan las mujeres peruanas en redes sociales?. Obtenido de Diario Gestión: https://gestion.pe/tecnologia/horas-dia-pasan-mujeresperuanas-redes-sociales-130279

- IPSOS. (2018). Perfil del ama de casa en el Perú. Obtenido de IPSOS: https://www.ipsos.com/es-pe/perfil-del-ama-de-casa-peruana-2018

- IPSOS (2018). Amas de casa desean dejar el nido y volar muy alto. Obtenido de IPSOS: https://www.ipsos.com/sites/default/files/ct/publication/documents/201809/el_ama_de_casa_desea_dejar_el_nido_y_volar_muy_alto.pdf

- Kantar Worldpanel. (2017). Estilo de vida de las latinas y peruanas. Obtenido de Kantar Worldpanel: https://www.kantarworldpanel.com/pe/Noticias/Estilo-de-vida-de-laslatinas-y-peruanas 
- Kantar Worldpanel. (2019). ¿Cómo cuidan los peruanos la alimentación de sus hijos?. Obtenido de Kantar Worldpanel: https://www.kantarworldpanel.com/pe/Noticias/Cmocuidan-los-peruanos-la-alimentacin-de-sus-hijos

- La República. (2019).¿Qué es la canasta básica familiar y para qué sirve?. Obtenido de La República: https://larepublica.pe/economia/1417724-canasta-basica-familiarsirve-inei-2019

- Merca 2.0. (2017). Las mamás que trabajan lideran el uso de las redes sociales.

Obtenido de Merca 2.0: https://www.merca20.com/las-mamas-que-trabajan-lideran-enel-uso-de-las-redes-sociales/

- Mercado Negro. (2028). Conoce las tendencias que activarán el consumo en el 2019. Obtenido de Mercado Negro: https://www.mercadonegro.pe/conoce-las-tendenciasque-activaran-el-consumo-en-el-2019/

- Quiñonez, C. (2019). Estrategias con Calle. Lima: Paidos.

- Villafaña, G. (2007). Educación Visual: Conocimientos Básicos para el Diseño. México: Trillas 


\begin{abstract}
ANEXOS
- Se aplicó una encuesta a 35 personas del público objetivo, éstos fueron los resultados: (Posteriormente, en una siguiente etapa, se aplicó la misma encuesta a 111 personas del P.O.)
\end{abstract}

\title{
¿Qué edad tienes?
}

35 respuestas

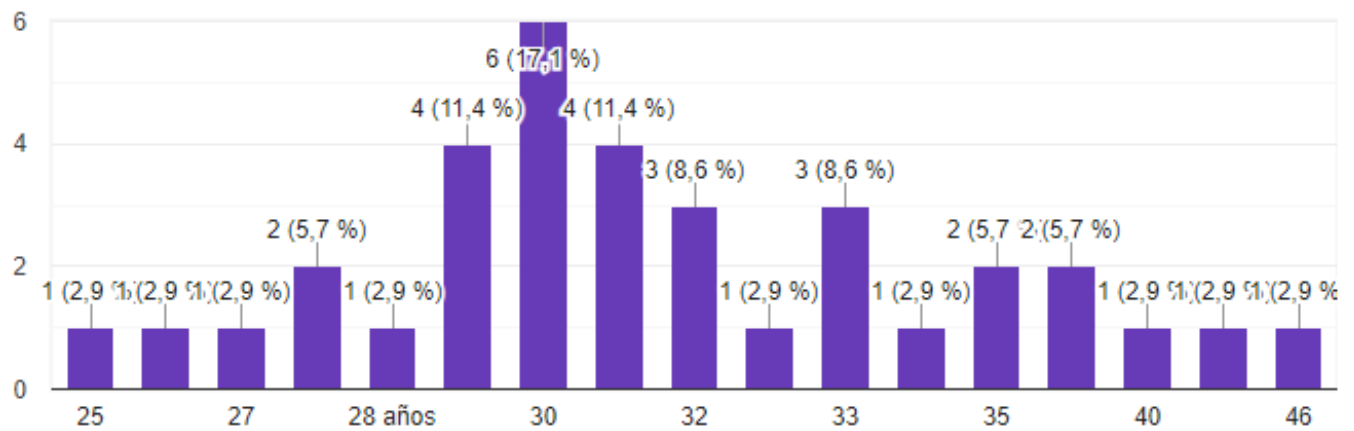

¿Cuántos hijos tienes?

35 respuestas

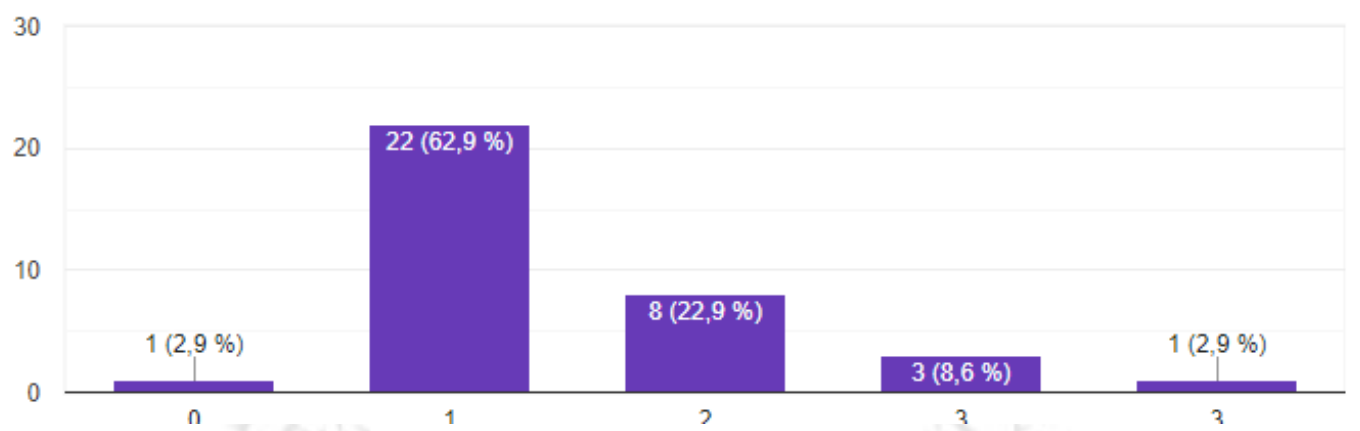

¿Qué pasatiempos realizas cuando tienes tiempo libre?

Leer

Hacer compras

Ver tele

Deporte y lectura

Ninguno

Gym

Deporte

Bailar, salir a pasear

Veo nextflix 
Hacer ejercicios

Gym is

2

Ver tele, ir a tomar un café, pintar en cerámica

Ver películas o series

Gimnasio

Pasear en familia

Salir a caminar

Llenar pupiletras y pintar

Ver tele

Voy de comprar, cine, paseo a los juegos con mi familia

Netflix, leer, cine, caminar

Compras online, ver tele

Pasear con mi hija

Ver tb, dormir, salir a comprar

Jugar con mi hija

leer, ver tele, bailar, salir

Ver películas

Tiempo con mi hija, crochet, yoga

Ir a comer con mi esposo

ejercicios o dormir

Leer, pasear con la familia, planear viajes

Ver una película

\section{¿Qué lugares prefieres para hacer compras para el hogar? (Puedes}

\section{marcar más de 1)}

35 respuestas

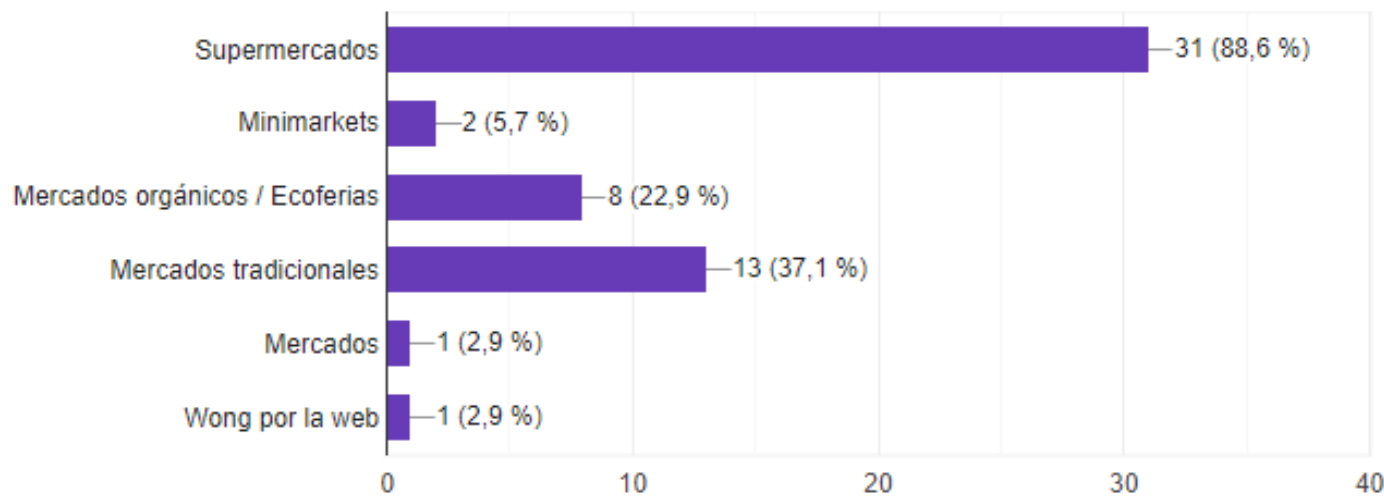

¿Cuál es tu principal preocupación al momento de elegir un producto para consumo de tus hijos?

\section{Calidad}

Que esté fresco.

Los componentes. Que tenga la menor cantidad de químicos, como colorantes, preservantes, saborizantes, edulcorantes y otros aditivos.

Que no contentan gluten ni mucha azúcar y sea saludable

Nutritivo y natural

Siempre reviso que no tenga "azúcar malo" 
Que sea orgánico

Bajas calorias y que sea sano

Nível de azucar

Información nutricional, niveles de azúcar concentrado y caducidad

Que no tenga mucha azúcar

Que sea nutritivo

Saludable

Que sea lo más natural posible

Ver la fecha de vencimiento y que estén frescas

Calidad

Que sea alimento

Los químicos

Producto Nutritivo

Que no contenga mucha azúcar

Nutrientes

Que no sea GMO o tenga pesticidas

Que sea saludable para mi familia

Aporte nutricional y precio

No saborizantes artificiales, no colorantes artificiales. Hablando de endulzantes yo prefiero cero pero si tiene que tener algun endulzante prefiero miel o azucar (sucralosa, jarabes, corn syrup, etc jamas)

Que sea sano

Valor alimenticio y que no sea saturado en grasas y/o azúcares

Salud

Que sea de buena calidad y sanos

\section{¿Qué factor consideras más relevante al momento de comprar un refresco (no gasificado)?}

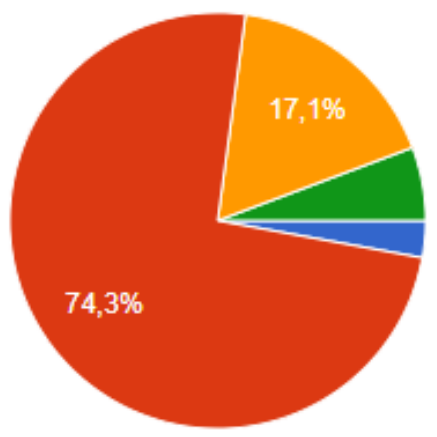


¿Haz preparado chicha morada de la manera tradicional?

35 respuestas

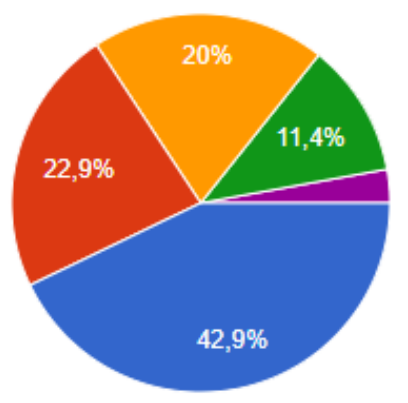

Sí, es fácil

Sí, es trabajosa

No, me gustaría aprender

- No, prefiero comprarla lista

- Mi empleada siempre la hace para todos los dias

11. Conoces los beneficios para la salud que tiene la chicha morada? 35 respuestas

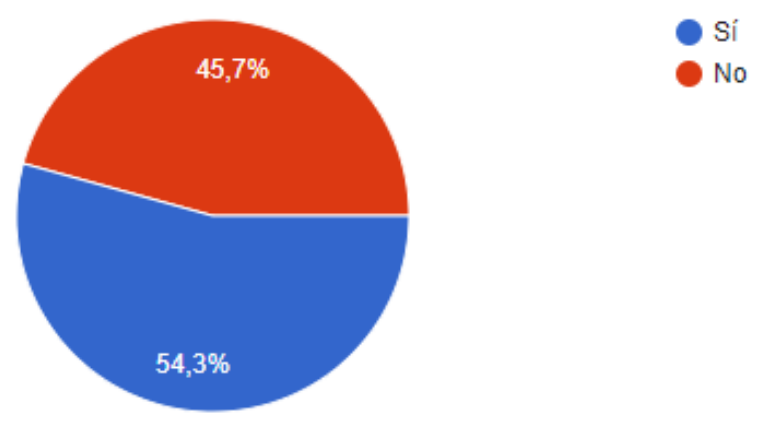

12. Si existiera un refresco basada en la verdadera concentración del maíz morado, libre de preservantes ni azúcar añadida, lo considerarías en las compras para consumo familiar?

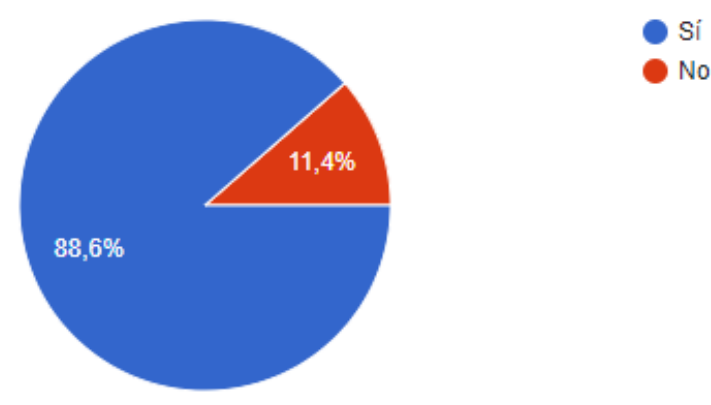


- Se realizaron 2 entrevistas a especialistas en su área:

Marisela Granados. Nutricionista particular

1. La chicha lleva diferentes ingredientes en su preparación, membrillo, cascara de piña, evidentemente el maíz morado, todos ellos aportan beneficios a la salud? Cómo cuáles? El maíz morado es un antioxidante natural, anti cancerígeno y tiene propiedades funcionales por sus compuestos bioactivos.

2. De los atributos del maíz morado, cual es el que más destacas?

Ese es el beneficio para la salud más resaltante del maíz. También es una excelente alternativa para utilizarlo como colorante natural. También tiene beneficios en la salud tales como enfermedades cardiovasculares, reducción del colesterol.

3. Incluyes o recomiendas la chicha natural en las dietas de mujeres con bastante actividad durante el día en edad entre 30 y 40 años? Si/No, porque? Si lo recomendaría.

4. Y en el caso de los niños?

Totalmente siempre y cuando no tengan azúcar añadido ni conservantes artificiales.

5. Si existiera un producto que te garantice el concentrado natural sin azucares añadidos, lo recomendarías?

Si lo recomendaría en mujeres entre 30 y 40 años sobre todo por su acción antioxidante (antiarrugas).

\section{Rita Sorogastúa. Comunicadora y Coach}

1. Hoy en día se habla con más fuerza sobre el empoderamiento femenino, ¿las mujeres han cambiado?

Hoy en día se habla mucho más sobre el empoderamiento femenino y sobre el feminismo, y el feminismo tiene dos vertientes según mi punto de vista. Una que es la más radical la cual prácticamente somos autosuficientes a tal punto que no es necesaria la energía del hombre y por otro lado el empoderamiento que te habla de la igualdad de oportunidades en la que se reconoce que ambas energías son necesarias. 
2. ¿Qué opinas sobre el título de "ama de casa" paras las mujeres que asumen este rol? Ellas se sienten identificadas?

Te contaré que cada vez siento que se habla menos de la figura de ama de casa, y siento que de alguna manera se ha utilizado como un término peyorativo. Creo que es un título que realmente no empodera el verdadero rol a esa mujer que decide ser el sostén y equilibrio en el hogar y no sólo a nivel físico sino también emocional. No sabría precisar si realmente les gusta el término.

3. ¿Consideras que hay sectores en los que la mujer se dedica sólo a las tareas domésticas y los hijos?

En todos los niveles socioeconómicos hay mujeres que sólo se dedican a las tareas económicas y a sus hijos, lo veo en un sector $\mathrm{AB}$ y en un $\mathrm{CD}$.

4. ¿Cómo deberían hablarle las marcas a este segmento de la sociedad?

Yo creo que desde el empoderamiento. 